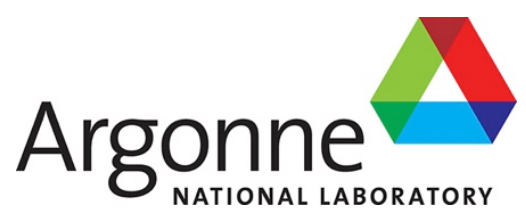

\title{
Regulatory Treatment of Low Frequency External Events under a Risk-Informed Performance-Based Licensing Pathway
}

Nuclear Science and Engineering Division, Argonne National Laboratory 


\section{About Argonne National Laboratory}

Argonne is a U.S. Department of Energy laboratory managed by UChicago Argonne, LLC under contract DE-AC02-06CH11357. The Laboratory's main facility is outside Chicago, at 9700 South Cass Avenue, Argonne, Illinois 60439. For information about Argonne and its pioneering science and technology programs, see www.anl.gov.

\section{DOCUMENT AVAILABILITY}

Online Access: U.S. Department of Energy (DOE) reports produced after 1991 and a growing number of pre-1991 documents are available free at OSTI.GOV (http://www.osti.gov/), a service of the US Dept. of Energy's Office of Scientific and Technical Information.

\section{Reports not in digital format may be purchased by the public from the} National Technical Information Service (NTIS):

U.S. Department of Commerce

National Technical Information Service

5301 Shawnee Rd

Alexandria, VA 22312

www.ntis.gov

Phone: (800) 553-NTIS (6847) or (703) 605-6000

Fax: (703) 605-6900

Email: orders@ntis.gov

Reports not in digital format are available to DOE and DOE contractors from the Office of Scientific and Technical Information (OSTI):

U.S. Department of Energy

Office of Scientific and Technical Information

P.O. Box 62

Oak Ridge, TN 37831-0062

www.osti.gov

Phone: (865) 576-8401

Fax: (865) 576-5728

Email: reports@osti.gov

\section{Disclaimer}

This report was prepared as an account of work sponsored by an agency of the United States Government. Neither the United States Government nor any agency thereof, nor UChicago Argonne, LLC, nor any of their employees or officers, makes any warranty, express or implied, or assumes any legal liability or responsibility for the accuracy, completeness, or usefulness of any information, apparatus, product, or process disclosed, or represents that its use would not infringe privately owned rights. Reference herein to any specific commercial product, process, or service by trade name, trademark, manufacturer, or otherwise, does not necessarily constitute or imply its endorsement, recommendation, or favoring by the United States Government or any agency thereof. The views and opinions of document authors expressed herein do not necessarily state or reflect those of the United States Government or any agency thereof, Argonne National Laboratory, or UChicago Argonne, LLC. 


\section{Regulatory Treatment of Low Frequency External Events under a Risk-Informed Performance-Based Licensing Pathway}

\section{Prepared by}

David Grabaskas, Ben Chen

Nuclear Science and Engineering Division, Argonne National Laboratory

Richard Denning

Consultant

September 2021 


\section{Acknowledgements}

This work is supported by the U.S. Department of Energy, Nuclear Energy Advanced Reactor Demonstration Program, Advanced Reactors Regulatory Development Area. The authors would like to thank Jim Kinsey for his support of this project.

In addition, the authors would like to thank the following for providing valuable insight and guidance on the project: Robert Budnitz, Nilesh Chokshi, M. K. Ravindra, Amir Afzali, Parthasarathy Chandran, Karl Fleming, Andrew Whittaker, Michelle Bensi, and numerous contributors from the advanced reactor industry. 


\section{Executive Summary}

Significant efforts are underway to develop and implement a risk-informed performance-based licensing framework for advanced reactors built on the establishment of an affirmative safety case. Such approaches offer the benefits of increased flexibility regarding key design and licensing decisions based on a detailed assessment and understanding of plant risk. These methods include the comprehensive analysis of scenarios that have historically been addressed through conservative and deterministic licensing analysis approaches, such as the evaluation of event sequences at frequencies of occurrence beyond the design basis.

While the detailed analysis of low frequency events provides insights that can help justify alternative treatments to past conservatism, the findings are dependent on the quality and confidence associated with the analyses. The assessment of external hazards presents a unique challenge, as their potential frequency of occurrence, especially of large magnitude events, is inherently uncertain given the long return periods in question.

The current project seeks to further explore the regulatory treatment of low frequency external events as part of a risk-informed performance-based framework. The goals are to identify the benefits and challenges of such approaches for advanced reactor vendors and to aid in the development of consistent and appropriate methodologies. As part of this effort, the current report summarizes initial project findings, with a focus on the evaluation of the seismic hazard. This includes an exploration of the implementation of a risk-informed performance-based approach through an example analysis.

Based on the identified challenges associated with the probabilistic treatment of low frequency event sequences, additional performance-based methods were explored as complementary tools for demonstrating regulatory compliance. The report highlights key challenges and opportunities associated with the methods and outlines recommendations and future activities to assist with their implementation. 


\section{Table of Contents}

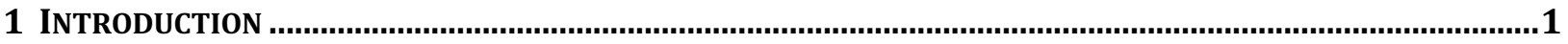

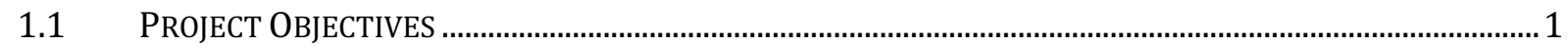

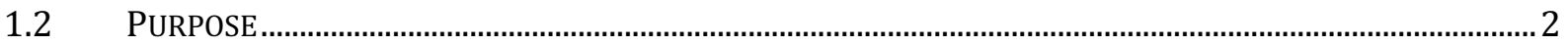

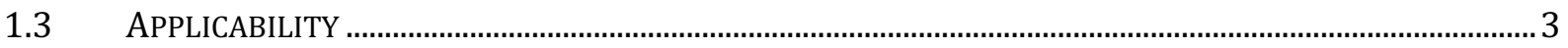

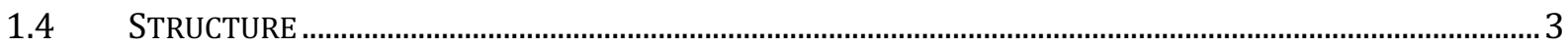

2 BACKGROUND ON EXTERNAL HAZARD REGULATION ...........................................................................

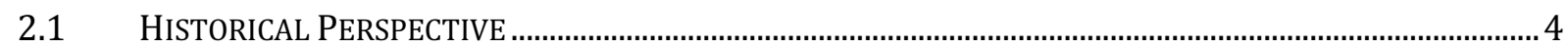

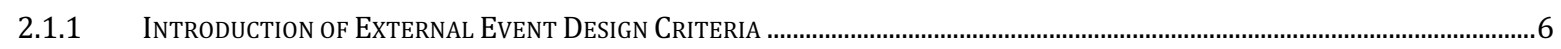

2.1.2 ESTABLISHMENT OF AN INDEPENDENT REGULATORY AUTHORITY ………………………………...................................................

2.1.3 TRANSition to Risk-InFormed, PERFormance-BASEd REGULATION ........................................................................................

2.1.4 Individual Plant EXAMINATION OF EXTERNAL EvENTS (IPEEE) ...............................................................................................

2.1.5 FUKUSHIMA EARTHQUAKE AND TSUNAMI ....................................................................................................................................9

2.2 CURRENT EXTERNAL HAZARD DESIGN BASIS ANALYSIS GUIDANCE ...................................................... 10

2.3 CURRENT REQUIREMENTS AND GUIDANCE FOR SEISMIC HAZARD ANALYSIS ......................................... 11

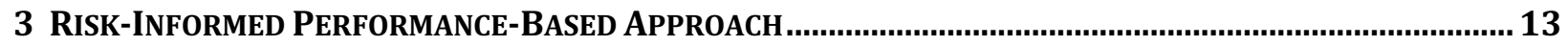

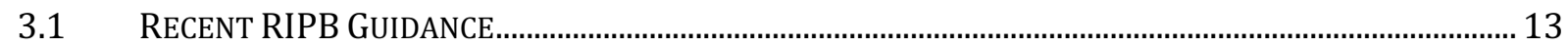

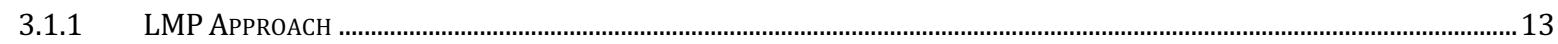

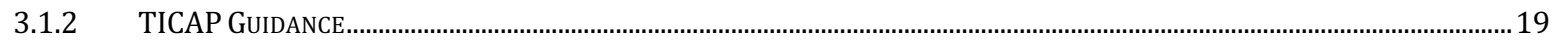

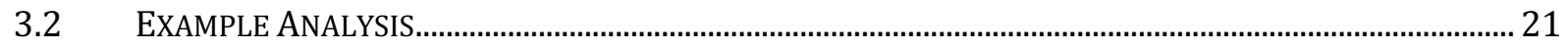

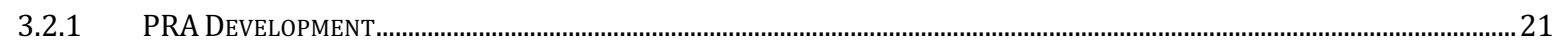

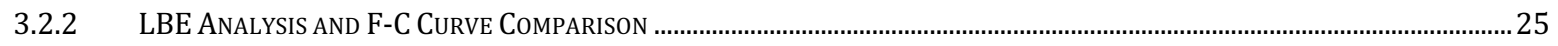

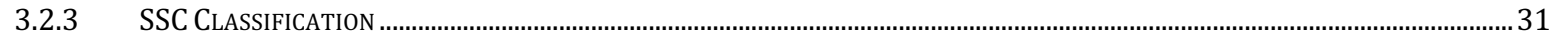

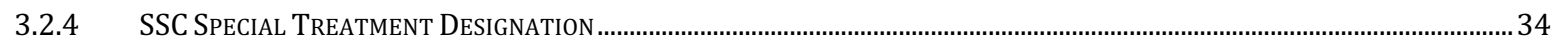

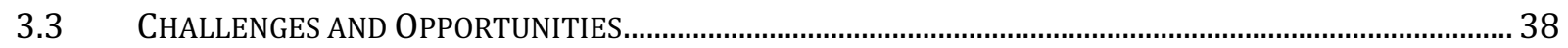

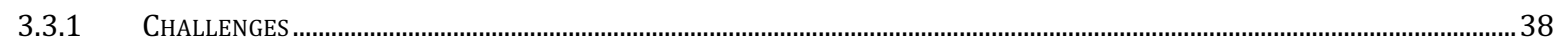

3.3.2 OPPORTUNITIES...................................................................................................................................................................... 40

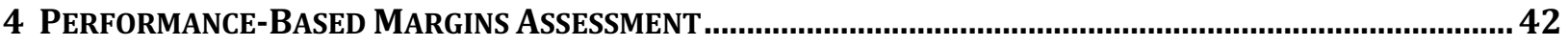

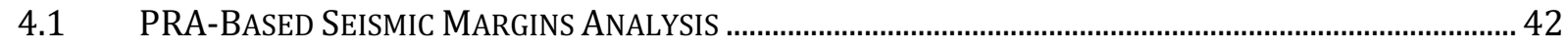

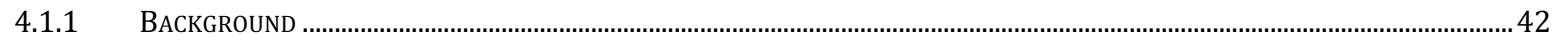

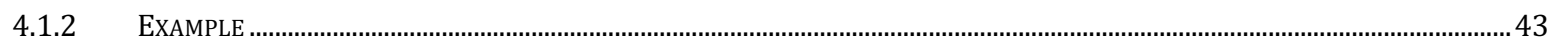

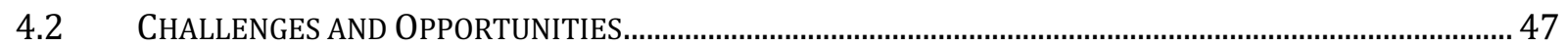

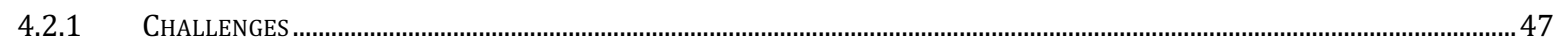

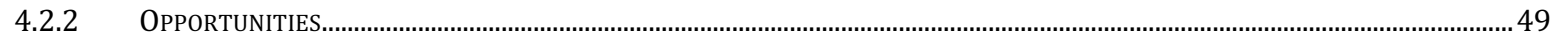

5 FINDINGS, RECOMMENDATIONS, AND NEXT STEPS ...........................................................................50

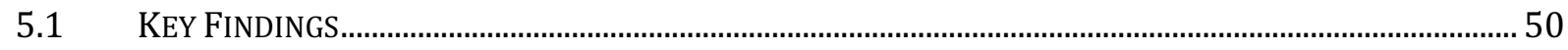

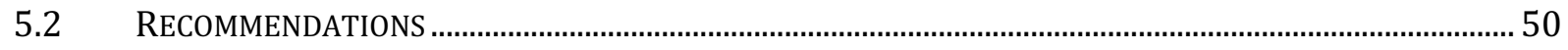

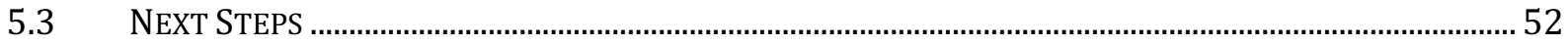

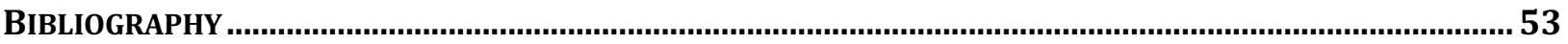

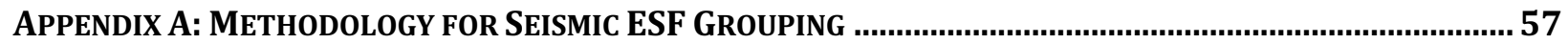




\section{Acronyms}

Acronym Definition

ACRS Advisory Committee on Reactor Safeguards

AEC Atomic Energy Commission

ANS American Nuclear Society

ANSI American National Standards Institute

AOO Anticipated Operational Occurrence

ASME American Society of Mechanical Engineers

BDBE Beyond Design Basis Event

BNL Brookhaven National Laboratory

CCDF Complementary Cumulative Distribution Function

CDF Core Damage Frequency

CSDRS Certified Seismic Design Response Spectra

DBA Design Basis Accident

DBE Design Basis Event

DBEHL Design Basis External Hazard Level

DBHL Design Basis Hazard Level

DF Design Factor

DID Defense-In-Depth

DOE Department Of Energy

EPRI Electric Power Research Institute

EPZ Emergency Planning Zone

ESF Event Sequence Family

GMRS Ground Motion Response Spectrum

HCLPF High Confidence of a Low Probability of Failure

HFO High Winds, Floods, And Other

IPE Individual Plant Examination

IPEEE Individual Plant Examinations on External Events

LBE Licensing Basis Event

LLNL Lawrence Livermore National Laboratory

LMP Licensing Modernization Project

LS Limit States

LWR Light-Water Reactor

MCA Maximum Credible Accident

MHE Maximum Hypothetical Earthquake

NPPs Nuclear Power Plants

NRC Nuclear Regulatory Commission

NSRST Non-Safety-Related with Special Treatment

NST Non-Safety-Related with No Special Treatment

OBE Operating Basis Earthquake

ORNL Oak Ridge National Laboratory 


$\begin{array}{ll}\text { PGA } & \text { Peak Ground Acceleration } \\ \text { PMF } & \text { Probable Maximum Flood } \\ \text { PMP } & \text { Probable Maximum Precipitation } \\ \text { PRA } & \text { Probabilistic Risk Assessment } \\ \text { PSF } & \text { PRA Safety Function } \\ \text { QA } & \text { Quality Assurance } \\ \text { QHOs } & \text { Quantitative Health Objectives } \\ \text { RA } & \text { Risk Achievement } \\ \text { RAP } & \text { Reliability Assurance Program } \\ \text { RG } & \text { Regulatory Guide } \\ \text { RIPB } & \text { Risk-Informed Performance-Based } \\ \text { RSF } & \text { Required Safety Function } \\ \text { SAMDAs } & \text { Severe Accident Mitigation Design Alternatives } \\ \text { SAR } & \text { Safety Analysis Report } \\ \text { SDC } & \text { Seismic Design Criteria } \\ \text { SEP } & \text { Systematic Evaluation Program } \\ \text { SMA } & \text { Seismic Margins Analyses } \\ \text { SPRA } & \text { Seismic Probabilistic Risk Assessment } \\ \text { SR } & \text { Safety-Related } \\ \text { SRM } & \text { Staff Requirements Memorandum } \\ \text { SSC } & \text { Structure, System, And Component } \\ \text { SSE } & \text { Safe Shutdown Earthquake } \\ \text { SSHAC } & \text { Senior Seismic Hazard Analysis Committee } \\ \text { SwRI } & \text { Southwest Research Institute } \\ \text { TICAP } & \text { Technology-Inclusive Content of Applications Project } \\ \text { UHRS } & \text { Uniform Hazard Response Spectra } \\ \text { VTR } & \text { Versatile Test Reactor }\end{array}$




\section{Introduction}

Significant efforts are underway to develop a risk-informed performance-based (RIPB) framework for advanced (non-light water) reactor licensing. These efforts aim to create an advanced reactor licensing pathway that permits the development of an affirmative safety case benefiting from the flexibility and detail associated with RIPB methods. Such an approach differs from the primarily prescriptive and conservative methods utilized to license the operating light-water reactor (LWR) fleet.

One such area of difference between the aforementioned licensing approaches is the methodology for the assessment of scenarios of very low frequency of occurrence, which were initially considered for LWRs mainly through the application of design margin and defense-in-depth (DID) philosophy (including robust containment, large distance to population centers, etc.). RIPB approaches, in contrast, attempt to evaluate these scenarios at a level of detail commensurate with their risk, which often necessitates an explicit treatment of their frequency and associated consequence. While this detailed information provides valuable insights into plant behavior and risk profile, it relies on the accuracy of the data and analyses supporting the assessment.

Events such as the Fukushima earthquake and tsunami and the flooding threat of Fort Calhoun Nuclear Station have highlighted the importance of external hazards in consideration of nuclear safety, given their ability to potentially defeat multiple layers of plant protection. However, the analysis of external hazards is dependent on the assessment of hazard frequency and severity, which is inherently uncertain, especially at return periods far beyond the timeline of human records. Therefore, the treatment of low frequency external events has the unique challenge to assure an adequate level of protection, with an appropriate level of confidence, against an innately uncertain threat.

\subsection{Project Objectives}

To assist the advanced reactor industry in future licensing efforts and support the development and implementation of RIPB licensing approaches, the DOE Advanced Reactor Demonstration Program Regulatory Development area initiated a project at Argonne National Laboratory to examine the regulatory treatment of external hazards as part of a RIPB licensing framework. Specifically, the project's focus is on the analysis and impact of low frequency external events (as defined below) on licensing decision-making. Questions regarding the appropriate treatment of low frequency external events as part of advanced reactor licensing have been highlighted by the advanced reactor industry [1] and also identified as part of the Versatile Test Reactor (VTR) project efforts. To address this topic, the project has several main objectives:

- Explore the analysis of low frequency external events when utilizing a probabilistic hazard/fragility-based approach according to the requirements of the ASME/ANS/ANSI Non-LWR PRA Standard [2].

- Examine the impact of low frequency external events on licensing decision-making as part of the development of an affirmative safety case when using RIPB approaches. Such decisions include event sequence categorization, structure, system, and component (SSC) classification, and DID evaluations. 
- Assess the historical basis for current regulation and guidance regarding the treatment of low frequency external events during reactor licensing.

- Evaluate the consistency and appropriateness of available regulatory approaches for the analysis of low frequency external events and, if necessary, recommend pathways to address identified challenges.

- To the extent practical, foster the adoption of common analysis approaches and regulatory treatments for external hazards, commensurate with their level of risk.

For the current work, the term "external events" refers to those event sequences with external hazard initiators. This includes all applicable external hazards for the design and site under consideration, as the ASME/ANS/ANSI non-LWR PRA standard permits the assessment of any external hazard through a probabilistic approach [2]. The term "low frequency" is defined as external events below 1E-4 per plant year, as to align with the guidance discussed in the following sections.

\subsection{Purpose}

The current work serves several purposes to assist with RIPB licensing framework development and implementation, as outlined below:

- Provide preliminary findings regarding the evolution of the regulatory treatment of external events in the U.S, including current guidance addressing low frequency seismic events.

- Based on available guidance, describe and demonstrate the treatment of low frequency seismic events as part of a RIPB framework. Identify the challenges and opportunities associated with the approach.

- As necessary, identify and demonstrate approaches that could be utilized in a complementary fashion to the RIPB framework to evaluate low frequency seismic events. Identify relevant challenges and opportunities.

- Provide recommendations for next steps, including the identification of areas of further research.

For the current effort, the RIPB framework developed by the Licensing Modernization Project (LMP) and associated Technology-Inclusive Content of Applications Project (TICAP) was selected, given recent endorsement by the U.S. Nuclear Regulatory Commission (NRC) [3]. While the project scope includes the regulatory treatment of all external hazards, preliminary work has focused on seismic evaluations. This selection was made for several reasons. First, there is significant guidance available regarding RIPB seismic evaluation methodologies, including recent efforts by the Southwest Research Institute (SwRI) [4]. Second, seismic may be the dominant external hazard for many sites under consideration for advanced reactor deployment. Lastly, seismic evaluations are an area of significant recent regulatory consideration following the events at Fukushima Daiichi. 


\subsection{Applicability}

It is understood that non-LWRs span a range of sizes and applications. Because of this, the pathway selected for reactor licensing will likely differ depending on the individual characteristics of the specific system, site, and purpose. The approaches and analyses discussed in the current work are of most interest to a subset of non-LWR designs, with the characteristics outlined below:

- Magnitude of potential source term: The radionuclide inventory within the plant, including the core and/or associated systems, is of sufficient magnitude and form that certain event sequences may potentially result in offsite doses at or above the consequence target defined in the LMP approach (discussed in Section 3.1.1).

- Site characteristics: The external hazards associated with the selected site or bounding site are of sufficient severity such that they may warrant additional design consideration to prevent potential radionuclide release in exceedance of consequence targets.

The analyses and evaluations presented here are most applicable to reactors that satisfy both criteria. For reactor designs with smaller potential source term or sited at locations with less severe external hazard threats, alternative approaches, such as deterministic or bounding analyses, may be sufficient for demonstrating design acceptability.

\subsection{Structure}

To provide initial findings on the tasks outlined above, the current work is structured as follows. Section 2 provides background information on external event regulation and guidance, including historical perspective and current seismic requirements. This is followed by Section 3, which details the current status of the LMP RIPB advanced reactor licensing framework and the associated TICAP guidance. A seismic demonstration analysis is also provided in this section utilizing the available guidance. Section 4 explores alternative performance-based approaches that could be used in conjunction with, or as part of, the LMP methodology. Lastly, Section 5 highlights key findings and suggested next steps.

It is important to note that example analyses provided in this document are to demonstrate the application of the methods discussed. However, external hazard analyses often require detailed and complex assessments. While efforts were made to develop example analyses that are representative of the key characteristics of the approaches, the required simplifications may not capture all important aspects regarding such assessments. 


\section{Background on External Hazard Regulation}

This section provides background on the regulatory treatment of external hazards to inform the subsequent discussion of analysis approaches described in Sections 3 and 4. A review of the evolution of regulatory considerations is provided first. As the central focus of the current effort is the regulatory treatment of seismic events, the final subsection provides an overview of current guidance on regulatory seismic evaluations.

\subsection{Historical Perspective}

As the nuclear industry has matured, it has become apparent that, although the concept of "defensein-depth" has been an effective approach to assuring the safe design of nuclear power plants (NPPs), external events, in particular seismic events and floods, have the potential to defeat multiple barriers of protection. This was made particularly apparent by the Fukushima accident in which a tsunami initiated by the Great Tohoku Earthquake [5] led to the meltdown of three reactors. Although some of the reasons the plant performed poorly in response to the event resulted from inadequate DID (e.g., failure to provide flood protection of emergency diesel generators), it was generally the lack of risk-informed design criteria that failed to recognize the threat of a low frequency, high magnitude tsunami. Historically in the United States, deterministic design criteria have been employed to protect against the failure of high hazard structures, such as dams and NPPs. The design criteria for very-low probability, high consequence natural hazards are based on a concept of "Probable Maximum" (such as Probable Maximum Precipitation, Probable Maximum Hurricane, Probable Maximum Flood), which are intended to reflect a very low frequency of a natural hazard but not an unphysical level of hazard (because there is a societal cost for overconservatism) [6]. Inherently, the Probable Maximum approach is to a large degree subjective. Probable Maximum criteria compound multiple conservatisms, making it difficult to assess the associated likelihood. To provide assurance that the Probable Maximum values are sufficiently conservative, a typical criterion is that the associated natural phenomenon design threat level should exceed any event of that nature experienced in recorded history for that region. In fact, a tsunami of comparable magnitude to the one initiated by the Great Tohoku Earthquake tsunami that inundated the Fukushima reactors had been experienced in the historical record for the Fukushima region [5]. In this review of the history of the regulatory treatment of external events, only natural phenomena hazards are considered. Fire risk, which has for historical reasons been termed an external event risk, is excluded, as are acts of sabotage, warfare, chemical releases from neighboring transportation accidents, neighboring industrial facility accidents, and cyber attacks.

In the Atomic Energy Act of 1946, the U.S. Atomic Energy Commission (AEC) was formed, primarily to develop nuclear weapons, but with a secondary function to develop peaceful uses of atomic energy [7]. In 1947, a technical advisory committee, the Safeguards Committee, was established to advise the AEC. The Safeguards Committee had a major impact on developing the safety philosophy at the time. That philosophy was to "imagine the worst possible accident and to design safety apparatus guaranteeing that it could not happen." [7] If the Committee could think of a plausible mishap worse than any discussed by the planner, the analysis was considered inadequate. In 1951 the AEC developed a requirement for a hazards-summary report for planned nuclear reactors, similar to what eventually became the preliminary safety analysis report. This report was to be completed prior to the decision to allow construction (although exceptions were made). The designer had to identify all known potential hazards and provide data and safety 
evaluations, including earthquakes of various intensities. However, no special requirements beyond building codes were developed for NPPs. The hazards-summary report also indicated steps taken to minimize public health risks ("risk" in its more general sense than currently associated with probabilistic risk assessment). The AEC staff reviewed the report and submitted it to the Safeguards Committee for review and approval.

In 1953, the United States promoted an international program for the development of peaceful uses of atomic energy, highlighted by the Atoms for Peace presentation at the United Nations by President Eisenhower. In that year, the Safeguards Committee and an industrial development committee were reorganized into the Advisory Committee on Reactor Safeguards (ACRS). The 1954 Atomic Energy Act gave the AEC responsibility for both the development and regulation of the atomic industry. The General Manager of the AEC informed the Joint Committee on Atomic Energy in 1956 that the agency's regulatory procedures were taking "all reasonable steps" to "minimize the probability of the occurrence of an accident," and that if an accident did occur, its consequences would be minimal.

To better understand the likelihood and consequences of a major accident at a nuclear plant, the AEC undertook a study led by Brookhaven National Laboratory (BNL). At the time, there had been some experimental work on fission product release from over-heated uranium dioxide fuel at Oak Ridge National Laboratory (ORNL) as a basis for estimating potential fuel releases. However, the design concepts were not well developed, and there were no objective means of estimating accident frequencies. The results of the study were published in 1957 as "A Study of Possible Consequences if Certain Assumed Accidents, Theoretically Possible but Highly Improbable, Were to Occur in Large Nuclear Power Plants," WASH-740 [8]. The probability estimates of severe accidents in the study were highly speculative. The analysis placed high confidence in the integrity of the containment building. The likelihood for substantial release from fuel and the reactor primary system ranged from 1:1000 to $1: 10,000$ per reactor year but for substantial release from containment ranged from 1:100,000 to 1:billion per reactor year, which are substantially smaller than current PRA assessments. However, the estimated consequences in terms of offsite release of radioactive material and early fatalities from radiation sickness for such a small assumed reactor power level (500 Mwt) were substantially higher than modern assessments, which are now based on an extensive database of severe accident research. Interestingly, there was no consideration of external events, such as seismic or flood events, as potential initiators of nuclear power plant accidents, other than a reference to possible "Acts of God" as initiators. As indicated in the following discussion, the potential importance of external hazards, such as seismic events, high winds, and floods as initiators of severe accidents was slow to be recognized in reactor regulations.

To support the development of siting criteria, the AEC developed the concept of a maximum credible accident (MCA) that could lead to a large release of radioactive material to the containment but would not fail containment [7]. It was presumed that by some mechanism, a large primary system pipe would rupture, pressurizing the containment and leading to substantial melting of fuel. The source term of radioactive material to containment for this accident was based on the report TID-14844 [9], which was used to assure that 25 rem whole-body doses (and 300 rem thyroid doses) were not exceeded at the exclusion area boundary and low population zone boundary for the plant. The 25 rem level was selected to provide margin to a dose level at which signs of radiation sickness would be expected and well below a level that could lead to early fatality. In recognition of the potential hazard associated with seismic events, a reactor could not be sited within one-half 
mile of a known earthquake fault. Although there was a recognition that seismic activity should impact siting and design, there were no NPP-specific constraints imposed associated with the potential impacts of flooding or high winds on accident potential.

\subsubsection{Introduction of External Event Design Criteria}

There were five U.S. nuclear power plants in the U.S. designed to commercial National Building Code seismic standards, for which construction was initiated in the mid-1960s prior to the establishment of special seismic design requirements for safety-related (SR) SSCs. Except in areas of known high seismicity, the loads from high lateral winds dominated the seismic loads. Thus, for these early designs, seismic loads had little impact on design or construction. The National Building Code (UBC-67) lateral peak ground accelerations (PGAs) were based on return periods of 50 to 100 years, which correlate to Modified Mercalli intensity levels on the order of $0.1 \mathrm{~g}$ PGA. At this level, structural damage is not expected even for structures not designed to withstand earthquakes. Although this PGA is low relative to current standards, at the time, structural response was based on elastic analysis, and whereas today, credit is allowed for inelastic behavior [10]. In 1963 Lockheed Aircraft Corporation and Narver, under contract to the AEC, prepared guidelines on existing seismic design criteria, methods of seismic analysis, and nuclear power plant specific hazards [11]. Other than recognizing that building codes vary by region depending on seismicity, this guide does not indicate a need for special criteria associated with NPP risks. The guide identifies the containment building as a robust tertiary barrier to the release of radioactive material to the environment unlikely to fail in a seismic event even if the other barriers fail.

In 1966, the AEC defined a "Maximum Hypothetical Earthquake (MHE)," as the largest earthquake in recorded history that had occurred within $300 \mathrm{~km}$ of the site with its epicenter intensity moved to the site." [10] An example of the impact on plant requirements is the Connecticut Yankee NPP originally designed for $0.03 \mathrm{~g}$ PGA, which was re-evaluated as $0.17 \mathrm{~g}$ PGA after the plant was already under construction. The MHE nomenclature was redefined in the 1970 s as the Safe Shutdown Earthquake (SSE), and an additional characteristic was defined as the Operating Basis Earthquake (OBE). Although the OBE was typically characterized by $1 / 3$ the PGA of the SSE, more conservative criteria and damping values were specified, such that in some instances, the OBE actually established the design limit [10]. If a plant were to be exposed to the vibratory loads of an SSE, SR SSCs would be expected to continue to provide their safety function, and there would be no significant release of radioactive material from the plant. Nevertheless, before restarting the plant, it would be necessary to provide assurance to the regulatory authority that the safety of the plant had not been compromised. In contrast, if the vibratory loads do not exceed the OBE, the plant would not be required to shut down unless critical safety functions have been identified as failed.

In 1967, the AEC developed General Design Criteria, which established high-level regulatory requirements for external hazards, including seismic design requirements to support applications for Construction Permits for NPPs [12]. Criterion 2 stated, "Those systems and components of reactor facilities which are essential to the prevention of accidents which could affect the public health and safety or to mitigation of their consequences shall be designed, fabricated, and erected to performance standards that will enable the facility to withstand, without loss of the capability to protect the public, the additional forces that might be imposed by natural phenomena such as earthquakes, tornadoes, flooding conditions, winds, ice and other local site effects." The design bases so established shall reflect "appropriate consideration of the most severe of these natural 
phenomena that have been recorded to reflect uncertainties about the historical data and their suitability as a basis for design."

The SSCs for which protection must be provided against external hazards were identified in Regulatory Guide (RG) 1.29 (originally Safety Guide 29) [13] as those necessary to assure:

(1) the integrity of the reactor coolant pressure boundary

(2) the capability to shut down the reactor and maintain it in a safe shutdown condition, or

(3) the capability to prevent or mitigate the consequences of accidents which could result in potential offsite exposures comparable to the 10CFR100 limits [14].

In August of 1973, the AEC issued RG 1.59 [6] establishing detailed guidelines for determining the magnitude of the Design Basis Flood complying with Criterion 2 of the General Design Criteria. The guide uses the term probable maximum flood (PMF) as a very conservative flood level consistent with the location of the plant near a river, lake, or seashore. Combinations of conservative assumptions are made in the analyses, such as the Probable Maximum Precipitation (PMP) in combination with waves, such as the wave caused by multiple dam failures associated with a seismic event. Along lakeshores and coastlines, flood levels are associated with hurricanes, severe surges, and seiches superimposed with waves. Because of the combination of improbable events, it is difficult to assign a value to the frequency of a design basis flood. The data to support the determination of the design levels are typically based on the U.S. Army Corps of Engineers, National and Oceanic and Atmospheric Administration, and the U.S. Geologic Survey criteria.

\subsubsection{Establishment of an Independent Regulatory Authority}

In 1975, the NRC was formed, officially separating regulatory oversight functions from reactor development and representing a turning point in regulatory thought. Previously, in 1973 the AEC had initiated work on a quantitative probabilistic risk assessment of nuclear power plants, which was published in 1975 under the NRC as "The Reactor Safety Study, WASH-1400 (using the AEC's prefix for reports) [15]. The principal focus of WASH-1400 was the treatment of internally initiated events (e.g., initiated by equipment failure or loss of offsite power combined with hardware failures). Although the likelihood of various external forces such as earthquakes, floods, and tornadoes that could cause accidents was also analyzed, the treatment of external event risk in WASH-1400 was generally limited. WASH-1400 concluded that seismic events would not be important contributors to nuclear power plant risk.

Shortly following the transition from the AEC to the NRC, a Standard Review Plan (NUREG0800) was issued, providing reviewers guidelines for evaluating new applications for the construction of NPPs. To evaluate the extent to which previously approved applications satisfied these new criteria, a Systematic Evaluation Program (SEP) was undertaken in 1977 for a sample of ten older plants [16]. The SEP program identified the following aspects of natural phenomena hazards that should be reviewed for operating reactors:

SEP Issue 1.2 Dam Integrity and Site Flooding

SEP Issue 1.3 Site Hydrology and Ability to Withstand Floods

SEP Issue 1.5 Tornado Missiles

SEP Issue 2.1 Severe Weather Effects on Structures

SEP Issue 2.4 Seismic Design of SSCs 
SEP Issue 3.1.1 Shutdown Systems

SEP Issue 3.1.2 Electrical Instrumentation and Controls

The SEP issues were ultimately resolved in 1995 based on insights gained from the Individual Plant Examinations on External Events (IPEEE) study (as discussed in Section 2.1.4).

In 1978, the NRC initiated a Seismic Safety Margins Program at Lawrence Livermore National Laboratory (LLNL) [17], which developed a seismic methodology, including methods for the treatment of common cause failures. The first full-scope PRAs to realistically address external events were performed in this time period, including the Zion Probabilistic Safety Study [18]. In 1982 the NRC assembled a working group of government and industry PRA practitioners to develop a PRA Procedures Guide [19], which in addition to procedures for the analysis of internal event risk, includes guidelines for the performance of external event risk assessments, including seismic, wind and flood risks. Although the Procedures Guide supported the use of screening criteria to enable PRA analysts to ignore events that provide a negligible contribution to risk, it does not provide specific screening criteria for different natural hazards, which could have provided a basis for the screening of the risk associated with a very low probability event (e.g. the risk associated with a meteorite impacting an operating nuclear power plant or a lower bound frequency for the analysis of a seismic event).

\subsubsection{Transition to Risk-Informed, Performance-Based Regulation}

Despite initial reluctance to base regulation on risk analysis, the potential benefits of risk-informing regulations and establishing risk metrics to support the regulatory oversight of operating plants led to increasing reliance on risk assessment. In 1986 the NRC issued the Safety Goals Policy Statement [20] with the objective of assuring that NPPs would introduce "insignificant" incremental risk to members of the public relative to other risks to which the public is exposed. Whereas WASH-1400 had compared NPP accident risks with risks experienced by the U.S. population as a whole, the safety goals addressed the risks to people living in the near neighborhood of a plant. In addition to qualitative safety goals, the policy statement provided the two quantitative health objectives (QHOs) associated with the fatality risk to people within one mile of the plant and cancer fatality risk to people within ten miles of the plant.

In 1989, NUREG-1150 [21] was issued as a reanalysis of the two WASH-1400 plants, as well as three additional plants, with methods that had been developed by a decade of research. The results of NUREG-1150 indicated that the five plants analyzed satisfied the QHOs by a large margin, including associated uncertainties in the analysis. External events analyses were performed for two of the five plants. Based on conservative analyses, wind and flood risks were screened from the analysis. However, the seismic risk values were assessed to be comparable to the internal event risks for the two plants but had very broad uncertainties. Separate seismic hazard curves were obtained from the elicitation of expert judgment for an LLNL team of experts and for an EPRI team of experts that had significant differences, with the LLNL team's assessment providing a substantially higher seismic threat than the EPRI team. To resolve the differences and to provide a methodology for future elicitations, an approach to incorporating differences in expert judgments regarding the seismic hazard at a site was developed by a Senior Seismic Hazard Analysis Committee (SSHAC) [22]. 


\subsubsection{Individual Plant Examination of External Events (IPEEE)}

Because of the recognized safety insights obtained from PRAs that had been performed for a few specific nuclear plants, the NRC established a requirement for Individual Plant Examination (IPE) risk studies for internal events for all plants in 1989 [23] and expanded that to include IPEEE in 1991 [24]. The findings of the IPEEE studies, provided in NUREG-1742 [25], include the following:

Seismic Risk Analysis: Two types of analyses were performed, seismic probabilistic risk assessments (SPRAs) and seismic margins analyses (SMAs) in which an assessment is made of the high probability of a low confidence of failure (HCLPF) for safety-significant SSCs and the plant as a whole. With respect to the SPRA results, most plants reported seismic core damage frequencies (CDFs) between 1E-5 per year and 1E-4 per year. The second group fell between 1E-6 per year and 1E-5 per year. Only a few plants reported frequencies greater than 1E-4 per year or less than 1E-6 per year. With respect to the SMA results, the margins of older plants were reported to be similar to those of newer plants constructed to more stringent criteria, indicating that those designs had been upgraded appropriately in the interim. In no cases was the reported plant HCLPF value less than the associated plant SSE. Potential vulnerabilities were identified for low-ruggedness relays (with the potential for relay chatter) and for block walls in several of the IPEEEs.

High Winds, Floods, and Other (HFO) External Events: One of the requirements of the IPEEE was the performance of a walk-down to search for vulnerabilities. Based on whether the plant conformed to the NRC's Standard Review Plan (NUREG-0800), plants were required to determine whether the original plant design criterion was acceptably low (less than $1 \mathrm{E}-5$ per year). If not, the plant could either perform a bounding analysis to show that the associated CDF contribution was less than 1E-6 per year or perform an external events PRA. For those cases in which risk analysis was performed, for high winds and tornadoes, CDF results varied from less than $2 \mathrm{E}-7$ per year to $6 \mathrm{E}-5$ per yr. For external floods, CDFs varied from $2 \mathrm{E}-8$ per year to $7 \mathrm{E}-6$ per year. One plant reported an improvement in door penetration seals to protect against external flooding resulting in a decrease in CDF from 1E4 per year to $1 \mathrm{E}-7$ per year.

\subsubsection{Fukushima Earthquake and Tsunami}

On March 11, 2011, the Great Tohoku magnitude 9.0 earthquake impacted the four Fukushima Daiichi NPPs, but more importantly, produced a massive tsunami that over-flowed the plant's tsunami barrier, flooded the plants, and led to melt-down of the three units operating at the time of the event [5]. In response, the NRC undertook a number of actions, including requirements for U.S. plants to review the potential for seismic or flooding-induced core meltdown accidents. Considerable concern was raised regarding vulnerability to upstream dam failures, as well as the potential for cascading dam failures. A requirement was also developed for additional safety equipment, referred to as FLEX equipment, which would be housed and protected against the initial threat but could be moved to the plant to provide long-term cooling capability.

In July of 2011, The Near-Term Task Force Review of Insights from the Fukushima Daiichi Accident made "Recommendations for Enhancing Reactor Safety in the 21st Century," which laid the groundwork for many of the subsequent changes in reactor regulation, particularly with regards 
to external event hazards and beyond design basis accidents [26]. An important observation of the Task Force relates to what constitutes "adequate protection" as an evolving concept. Plants had largely been licensed and regulated within the context of established design bases for SR SSCs, technical specifications, safety-related programs (such as the plant's maintenance and fire protection programs), and compliance with associated restrictions, such as quality assurance standards. Some exceptions, requiring special safety requirements such as Station Blackout and Anticipated Transients without Scram, had been recognized as beyond design basis events requiring regulatory oversight. However, the results of PRAs, lessons learned from the TMI-2 accident, and lessons learned from the Fukushima accident have expanded NRC's treatment of beyond design basis accidents and extreme natural phenomena hazards beyond their design bases.

Although DID has long been an important element of the framework of NPP safety from the viewpoints of diversity and redundancy, the Fukushima accident demonstrated the need to extend the concept of DID to the consideration of extreme natural phenomena hazards and beyond design basis conditions (for example, failure to protect diesel generators from a low-frequency external flooding event). Recommendation 1 states: "The Task Force recommends establishing a logical, systematic, and coherent regulatory framework for adequate protection that appropriately balances defense-in-depth and risk considerations."

\subsection{Current External Hazard Design Basis Analysis Guidance}

As highlighted in the preceding subsection, Criterion 2 of the General Design Criteria (Appendix A to Part 50) provides criteria for Protection Against Natural Phenomena, as outlined below. The current wording has also been adopted as-is for all advanced reactor types as part of the Advanced Reactor Design Criteria in RG 1.232 [27].

Criterion 2: Design bases for protection against natural phenomena. Structures, systems, and components important to safety shall be designed to withstand the effects of natural phenomena such as earthquakes, tornadoes, hurricanes, floods, tsunami, and seiches without loss of capability to perform their safety functions. The design bases for these structures, systems, and components shall reflect: (1) Appropriate consideration of the most severe of the natural phenomena that have been historically reported for the site and surrounding area, with sufficient margin for the limited accuracy, quantity, and period of time in which the historical data have been accumulated, (2) appropriate combinations of the effects of normal and accident conditions with the effects of the natural phenomena and (3) the importance of the safety functions to be performed.

In the implementation of this criterion, the current guidance regarding the determination of design basis external hazards is varied, as outlined in Table 2-1. Frequency information has been utilized to inform the selection of the design basis level of several, but not all, external hazards. Of those that do incorporate frequency insights, there is no current consensus regarding the appropriate frequency of occurrence for the design basis external hazard level. 
Table 2-1: Regulatory Treatment of External Hazards (Adapted from Ref [28])

\begin{tabular}{lll}
\hline External Event & Guidance & Frequencies Considered \\
\hline $\begin{array}{l}\text { Precipitation } \\
\text { (rain, snow) }\end{array}$ & $\begin{array}{l}\text { R.G. 1.206 Combined License } \\
\text { Applications for NPPs }\end{array}$ & Historical information \\
Hurricanes & $\begin{array}{l}\text { R.G. 1.221 Design Basis Hurricane } \\
\text { and Hurricane Missiles for NPPs }\end{array}$ & $\begin{array}{l}\text { Design basis hurricane wind speeds } \\
\text { should correspond to an exceedance } \\
\text { frequency of 1E-7 per yr (calculated as } \\
\text { best estimate) }\end{array}$ \\
Tornadoes & $\begin{array}{l}\text { R.G. 1.76 Design Basis Tornado and } \\
\text { Tornado Missiles for NPPs }\end{array}$ & $\begin{array}{l}\text { Design basis tornado wind speed } \\
\text { should correspond to an exceedance } \\
\text { frequency of 1E-7 per yr (calculated as } \\
\text { best estimate) }\end{array}$ \\
& $\begin{array}{l}\text { Historical information } \\
\text { External Flooding }\end{array}$ & $\begin{array}{l}\text { R.G. 1.59 Design Basis Floods for } \\
\text { NPPs }\end{array}$ \\
Reismic & $\begin{array}{l}\text { R.G. 1.208 A Performance-Based } \\
\text { Earthquake Ground Motion }\end{array}$ & $\begin{array}{l}\text { A target value of 1E-5 per yr for the } \\
\text { mean exceedance frequency of the } \\
\text { onset of significant inelastic } \\
\text { deformation (detailed further in } \\
\text { Section 2.3) }\end{array}$ \\
\hline
\end{tabular}

\subsection{Current Requirements and Guidance for Seismic Hazard Analysis}

Detailed descriptions of seismic requirements and their current implementation are available (see refs [29-31]), and a brief overview is provided here to inform the discussion in subsequent sections. As mentioned in Section 2.1.1, the MHE nomenclature was redefined as the SSE and OBE in the 1970s. The current implementation of the SSE is defined in terms of both a $\mathrm{PGA}^{1}$ and response spectrum. Beginning in 1997, the SSE determination was guided by RG 1.165 [32], which utilized the basic principle that new reactors should be designed to earthquake levels (in terms of annual probability of exceedance) that are more conservative than the median design ground motions for a set of the current operating fleet [29]. Based on an analysis of 28 operating sites, an annual exceedance frequency of 1E-5 per year based on the median hazard curve was established.

In 2010, RG 1.165 was superseded by RG 1.208 [33], which offered a performance-based approach to defining a site-specific ground motion response spectrum (GMRS) based on the method in ASCE 43-05 [34]. The approach in RG 1.208 is fundamentally different than that in RG 1.165. While RG 1.165 utilized a hazard-consistent approach, RG 1.208 uses a derivation of the risk-consistent methodology in ASCE 43-05 [33]. In this approach, uniform hazard response spectra (UHRS) are defined at different annual exceedance frequencies. A design factor (DF) is established depending on the slope of the hazard curve and is utilized to calculate the GMRS. The details of this approach for the establishment of a SSE PGA will be discussed further in Section 4.1.

In parallel to the evolution of SSE determination, developments were also ongoing regarding the analysis of beyond design basis seismic events for new reactor licensees. SECY-93-087 [35] recommended that PRA insights support a margins-type assessment of seismic events for license

\footnotetext{
${ }^{1}$ PGA is typically determined based on the horizontal spectrum acceleration at $100 \mathrm{~Hz}$.
} 
applicants. The seismic margins approach recommendation included the consideration of a sequence-level HCLPF for all sequences leading to core damage or containment failure at a value twice that of the SSE. In other words, the HCLPF value ${ }^{2}$ of the seismic fragilities of those event sequences leading to core damage or containment failure was to be compared to a ground motion of twice the SSE, as an evaluation of beyond design basis accident performance. In response, EPRI recommended the use of a 1.5 multiplier, which was seen as more consistent with the operating fleet [35]. In the Staff Requirements Memorandum (SRM) in response to SECY-93-067 [36], the commission approved a multiplier value of 1.67 of the SSE.

In 2010, DC/COL-ISG-020 [37] further clarified the implementation of the PRA-based seismic margins analysis for new reactor applications. The event sequences considered in the margins analysis should include those leading to core damage or containment failures, including applicable sequences leading to the following containment failures:

(1) loss of containment integrity,

(2) loss of containment isolation, and

(3) loss of function for prevention of containment bypass. The operating modes to be considered include at power (full power), low power, and shutdown.

In addition, a plant-level HCLPF value should be determined, in terms of PGA, based on the sequence-level analysis. At the design stage, the analysis utilizes the certified seismic design response spectra ${ }^{3}$ (CSDRS) PGA to represent the SSE, while the GMRS PGA is utilized as the SSE for site-specific evaluations. If the plant-level HCLPF value is less than $167 \%$ of the SSE, then two options are available to the plant designer [37]:

1) The applicant identifies the affected SSCs and upgrades their capacity to ensure that the plant-level HCLPF capacity be maintained at the level of 1.67 times the SSE PGA.

2) The applicant performs full convolution of sequence fragility for all sequences with a potential to lead to core damage with the mean hazard curve to develop risk metrics to demonstrate that the seismic risk is acceptably low for the licensed plant. This option is reviewed and accepted by the NRC on a case-by-case basis.

Further guidance regarding the performance of HCLPF assessments and the viewpoint of the NRC on related technical aspects can be found in the Japan Lessons-Learned Project document [38]. Although this document is not directly applicable to new reactor licensing, certain discussions within the document are informative for subsequent sections of this report.

\footnotetext{
${ }^{2}$ HCLPF is measure of seismic ruggedness. HCLPF is defined as the earthquake motion level at which there is a high (95 percent) confidence of a low (at most 5 percent) probability of failure. Using the lognormal fragility model, the HCLPF capacity is expressed as $A_{m} \exp \left[-1.65\left(\beta_{R}+\beta_{u}\right)\right]$.

${ }^{3}$ The site-independent seismic design response spectra that have been approved under Subpart B, "Standard Design Certifications," of 10 CFR Part 52, "Licenses, Certifications, and Approvals for Nuclear Power Plants" (Ref. 5), as the seismic design response spectra for a nuclear power plant using an approved certified standard design [37].
} 


\section{Risk-Informed Performance-Based Approach}

This section explores the treatment of external hazards as part of a RIPB framework for advanced reactor licensing. This begins with a review of recent guidance from the LMP and TICAP efforts and is followed by an example seismic analysis. The section concludes with an overview of the challenges and benefits of the RIPB approach for external hazards, focusing on those events of a low frequency of occurrence.

\subsection{Recent RIPB Guidance}

For the current effort, the guidance from the LMP and TICAP were utilized as the RIPB licensing approach under consideration. The portions of guidance pertinent to external hazards analysis are briefly reviewed here, with complete details available in refs [39, 40].

\subsubsection{LMP Approach}

In the LMP approach, risk information and complementary deterministic analyses are utilized as part of the development of an affirmative safety case, which informs decisions regarding licensing basis event (LBE) selection, SSC classification, and the evaluation of DID. Figure 3-2 outlines the LMP process for LBE selection and evaluation using the event sequences identified within the PRA. Once identified, the LBEs are categorized based on their frequency of occurrence utilizing the regions depicted in Figure 3-1, which include the Anticipated Operational Occurrence (AOO), Design Basis Event (DBE), and Beyond Design Basis Event (BDBE) regions. This process is also intertwined with the identification of required safety functions (RSFs) and the selection of safetyrelated (SR) SSCs, as will be discussed. Design Basis Accidents (DBAs) are derived from those LBEs within the DBE region and are re-evaluated to demonstrate compliance with dose criteria utilizing only SR SSCs.

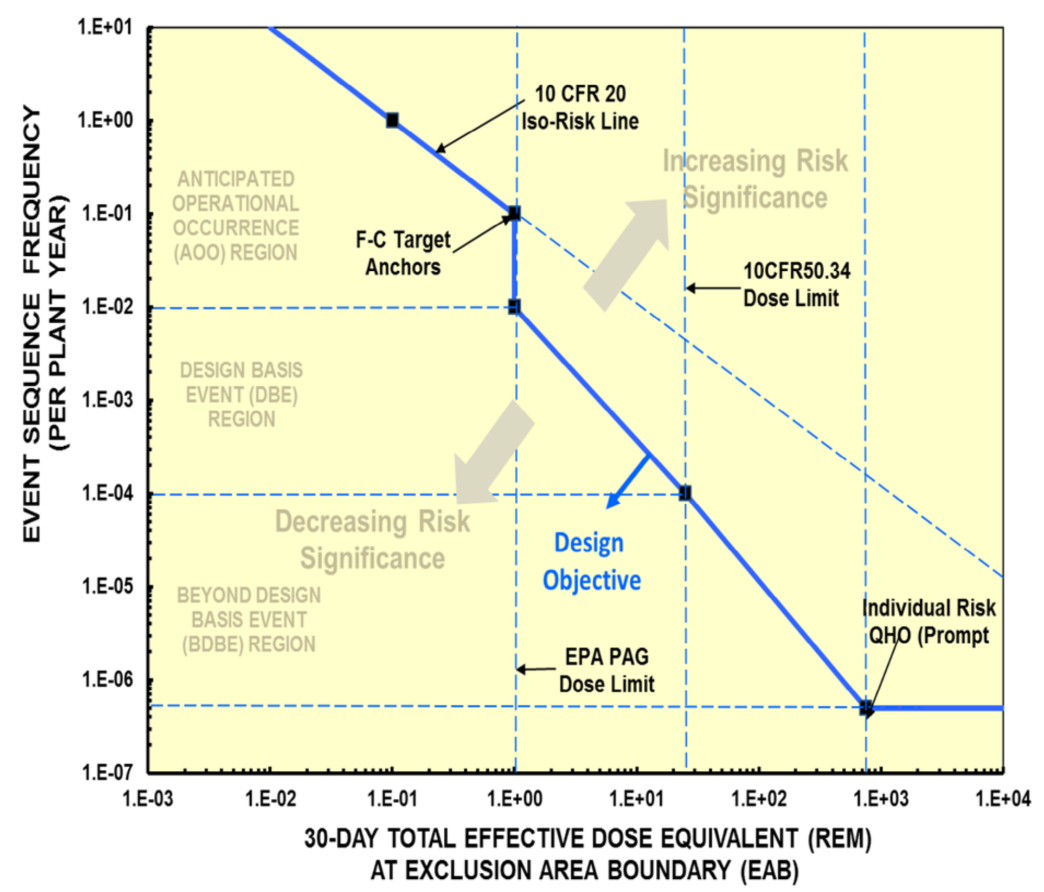

Figure 3-1: LMP Frequency-Consequence Target Curve [39] 


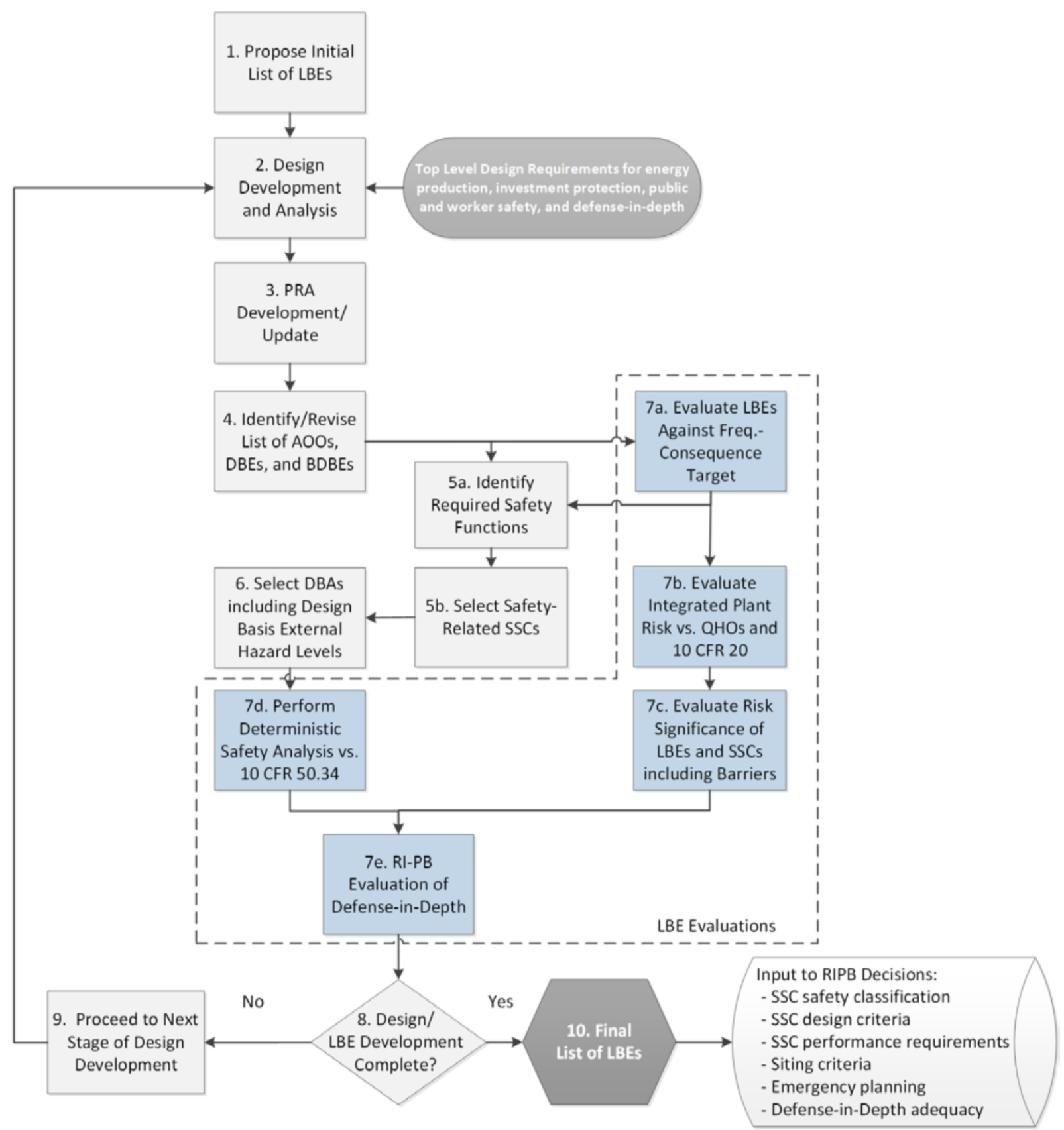

Figure 3-2: Process for Selecting and Evaluating LBEs [39]

Through this process, RSFs are identified that are necessary for the preservation of plant safety. The SSCs that perform the RSFs are identified (or selected) and are evaluated for safety classification. More formally, SSC classification is performed based on the criteria outlined below and utilizing the process shown in Figure 3-3. This includes the categorization of non-safety-related with special treatment (NSRST) SSCs.

\section{- Safety-Related:}

- SSCs selected by the designer from the SSCs that are available to perform the RSFs to mitigate the consequences of DBEs to within the LBE F-C Target, and to 
mitigate DBAs that only rely on the SR SSCs to meet the dose limits of 10 CFR 50.34 using conservative assumptions

- SSCs selected by the designer and relied on to perform RSFs to prevent the frequency of BDBE with consequences greater than the 10 CFR 50.34 dose limits from increasing into the DBE region and beyond the F-C Target

\section{- Non-Safety-Related with Special Treatment (NSRST):}

- Non-safety-related SSCs relied on to perform risk-significant functions. Risksignificant SSCs are those that perform functions that prevent or mitigate any LBE from exceeding the F-C Target or make significant contributions to the cumulative risk metrics selected for evaluating the total risk from all analyzed LBEs

○ Non-safety-related SSCs relied on to perform functions requiring special treatment for DID adequacy

\section{- Non-Safety-Related with No Special Treatment (NST):}

○ All other SSCs (with no special treatment required)

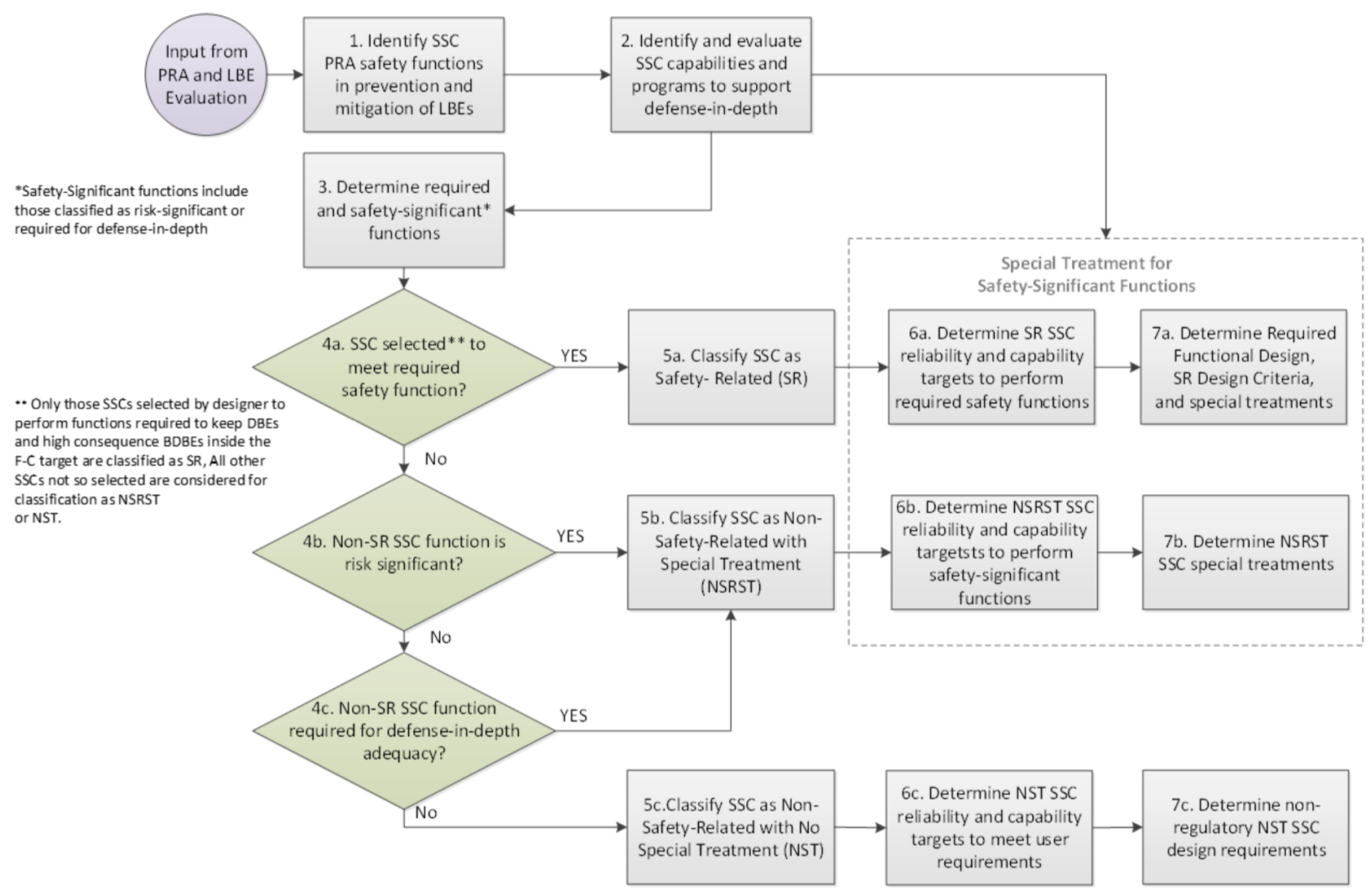

Figure 3-3: LMP SSC Classification Process [39]

DID adequacy is assured through qualitative and quantitative evaluations, as outlined by the guidelines in Table 3-1. The quantitative guidelines follow the categorization of LBEs and satisfaction of the QHOs with sufficient margin. Qualitative guideline examples include minimizing the challenges to SR SSCs and preventing an overdependency on single barriers or systems for plant safety. 
Table 3-1: LMP DID Adequacy Guidelines [39]

\begin{tabular}{|c|c|c|c|c|c|}
\hline \multirow{2}{*}{\multicolumn{2}{|c|}{ Layer $^{[\mathrm{a}]}$}} & \multicolumn{2}{|c|}{ Layer Guideline } & \multicolumn{2}{|c|}{ Overall Guidelines } \\
\hline & & Quantitative & Qualitative & Quantitative & Qualitative \\
\hline & $\begin{array}{l}\text { Prevent off-normal } \\
\text { operation and AOOs }\end{array}$ & \multicolumn{2}{|c|}{$\begin{array}{l}\text { Maintain frequency of plant transients } \\
\text { within designed cycles; meet owner } \\
\text { requirements for plant reliability and } \\
\text { availability }^{[b]}\end{array}$} & \multirow{5}{*}{$\begin{array}{l}\text { Meet F-C } \\
\text { Target for all } \\
\text { LBEs and } \\
\text { cumulative risk } \\
\text { metric targets } \\
\text { with } \\
\text { sufficient }^{[\mathrm{d}]} \\
\text { margins }\end{array}$} & \multirow{5}{*}{$\begin{array}{l}\text { No single } \\
\text { design or } \\
\text { operational } \\
\text { feature, }{ }^{[c]} \text { no } \\
\text { matter how } \\
\text { robust, is } \\
\text { exclusively } \\
\text { relied upon to } \\
\text { satisfy the five } \\
\text { layers of } \\
\text { defense }\end{array}$} \\
\hline & $\begin{array}{l}\text { Control abnormal } \\
\text { operation, detect failures, } \\
\text { and prevent DBEs }\end{array}$ & $\begin{array}{l}\text { Maintain frequency } \\
\text { of all DBEs } \\
<10^{-2} / \text { plant-year }\end{array}$ & $\begin{array}{l}\text { Minimize frequency } \\
\text { of challenges to SR } \\
\text { SSCs }\end{array}$ & & \\
\hline & $\begin{array}{l}\text { Control DBEs within the } \\
\text { analyzed design basis } \\
\text { conditions and prevent } \\
\text { BDBEs }\end{array}$ & $\begin{array}{l}\text { Maintain frequency } \\
\text { of all BDBEs } \\
<10^{-4} / \text { plant-year }\end{array}$ & $\begin{array}{l}\text { No single design or } \\
\text { operational feature } \\
\text { relied upon to meet } \\
\text { quantitative objective } \\
\text { for all DBEs }\end{array}$ & & \\
\hline & $\begin{array}{l}\text { Control severe plant } \\
\text { conditions and mitigate } \\
\text { consequences of BDBEs }\end{array}$ & \multirow{2}{*}{$\begin{array}{l}\text { Maintain individual } \\
\text { risks from all LBEs < } \\
\text { QHOs with } \\
\text { sufficient }^{[d]} \text { margins }\end{array}$} & \multirow{2}{*}{$\begin{array}{l}\text { No single barrier }{ }^{[c]} \text { or } \\
\text { plant feature relied } \\
\text { upon to limit releases } \\
\text { in achieving } \\
\text { quantitative } \\
\text { objectives for all } \\
\text { BDBEs }\end{array}$} & & \\
\hline & $\begin{array}{l}\text { Deploy adequate offsite } \\
\text { protective actions and } \\
\text { prevent adverse impact } \\
\text { on public health and } \\
\text { safety }\end{array}$ & & & & \\
\hline \multicolumn{6}{|c|}{$\begin{array}{l}\text { Notes: } \\
\text { [a] The plant design and operational features and protective strategies employed to support each layer should } \\
\text { be functionally independent. } \\
\text { [b] Non-regulatory owner requirements for plant reliability and availability and design targets for transient } \\
\text { cycles should limit the frequency of Initiating Events and transients and thereby contribute to the protective } \\
\text { strategies for this layer of DID. Quantitative and qualitative targets for these parameters are design specific. } \\
\text { [c] This criterion implies no excessive reliance on programmatic activities or human actions and that at least two } \\
\text { independent means are provided to meet this objective. } \\
\text { [d] The level of margins between the LBE risks and the QHOs provides objective evidence of the plant } \\
\text { capabilities for DID. Sufficiency will be decided via the IDP. }\end{array}$} \\
\hline
\end{tabular}

Within the LMP approach, the analysis of external hazards primarily centers on the determination of design basis hazard levels ${ }^{4}$ (DBHLs), which are the level of external hazard severity that SR SSCs are designed to withstand. The concept is to ensure that the design requirements of SR SSCs protect them against hazards with a frequency as low as 1E-4 per plant-year, which aligns with the frequency threshold for the DBE region.

The licensing impact of external events of lower frequency than DBHLs is implicit within other steps of the LMP process, such as the SSC classification process and DID evaluation. For example, as part of the SSC classification criteria, sensitivity analyses are performed for BDBE LBEs to identify important SSCs that may warrant NSRST designation. Similarly, DID evaluations examine

\footnotetext{
${ }^{4}$ Referred to as Design Basis External Hazard Levels or DBEHLs in NEI 18-04.
} 
the importance of particular SSCs and the possibility for common cause failures due to the impact of external hazards.

Since the focus of the current project is on low frequency events, which likely do not require evaluation for the identification of SR SSCs following the LMP guidance, the NSRST SSC designation and associated requirements are of primary interest. As outlined in NEI 18-04, the purpose of the NSRST designation is the assurance of the capability and reliability of SSCs necessary to perform risk-significant functions or those functions important to DID. The determination of these SSCs is through the sensitivity analyses performed in accordance with the criteria above. LMP adopted the definition of special treatment that is provided in Regulatory Guide 1.201 [41], which was developed for implementing 10 CFR 50.69:

"...special treatment refers to those requirements that provide increased assurance beyond normal industrial practices that structures, systems, and components (SSCs) perform their design-basis functions."

Therefore, for NSRST SSCs, special treatment requirements are those actions beyond normal industrial practices that provide reasonable confidence that the SSCs will perform their functions represented in the associated LBEs. Assurance is accomplished by achieving and monitoring the level of reliability and availability for the SSC that are determined to be necessary to meet the criteria of the associated LBE(s) [39]. Potentially applicable special treatment categories for NSRST SSCs are outlined in Table 3-2. NEI 18-04 notes that this table is general guidance only and should not be viewed as prescriptive. The applicability of any special treatment should be evaluated on a case-by-case basis and in the context of the SSC functions in the prevention and mitigation of applicable LBEs.

NEI 18-04 recommends that all NSRST SSCs should be incorporated into a Reliability Assurance Program (RAP), similar to that in SRP 17.4 [42], as the reliability and availability targets established in the RAP are used to focus special treatment requirements that are "necessary and sufficient" to achieve these targets. The capability and reliability targets for NSRST SSCs are derived from the LBEs responsible for the safety classification. The following subsection explores how the identified DBHLs and NSRST special treatment requirements related to external hazards could be documented within a Safety Analysis Report (SAR). 
Table 3-2: Summary of Potential Special Treatments for NSRST SSCs [39] Special Treatment Category $^{1} \quad$ Available Guidance $^{2}$

Document basis for SSC categorization by Integrated Decision-Making Process

Document evaluation of adequacy of special treatment to support SSC categorization

Change control process to monitor performance and manage SSC categorization

Reliability Assurance Program including reliability and availability targets for SSCs in performance of PRA Safety Functions

Design Requirements for SSC capability to mitigate challenges reflected in LBEs

Maintenance Program that assures targets for SSC availability and effectiveness of maintenance to meet SSC reliability targets

Licensee Event Reports

User provided Quality Assurance Program for nonsafety SSCs

Technical Specifications

Seismic design basis

Pre-service and risk-informed in-service inspections

Pre-service and in-service testing
Essentially the same as 10 CFR 50.69(e), Guidance in RG 1.201, NEI-00-04 for all SSCs

Essentially the same as 10 CFR 50.69(d), Guidance in Regulatory Guide 1.201, NEI-00-04 for RISC-1 $\mathrm{SSCs}$

Essentially the same as 10 CFR 50.69(e), Guidance in Regulatory Guide 1.201, NEI-00-04 for RISC-1 and RISC-2 SSCs

Essentially same as Reliability Assurance Program in SRP 17.4 for safety-significant SSCs, Guidance in SRP Chapter 19.3, ASME Section XI Reliability and Integrity Management Programs

Guidance in this guidance document, MHTGR Preliminary Safety Information mitigate challenges reflected in LBEs

Essentially same as 10 CFR 50.65 Maintenance Rule; link to MR consistent with 10 CFR 50.69 for RISC-1 (SR) and RISC-2 (NSRST) SSCs

Essentially same as 10 CFR 50.69(f), Guidance in Regulatory Guide 1.201, NEI-00- 04 for RISC-1 and RISC-2 SSCs

QA requirements consistent with SRP 17.4 (Reliability Assurance Program) User provided Quality Assurance (QA) Program for non-safety SSCs performance-based and not compliance based; guidance in SRP 17.5 Quality Assurance for non-safety-related SSCs, 10 CFR 50.69, SRP 1.201

10 CFR 50.36, SRP, MHTGR Preliminary Safety Information Document

Essentially the same as for existing reactors for SR SSCs 10 CFR 100 Appendix A

See Regulatory Guide 1.178

In-service testing needs to be integrated with Reliability Assurance Program

${ }^{1}$ The need for this special treatment for any NSRST is determined on a case-by-case basis, and when applicable, is applied to the specific functions to prevent and mitigate the applicable LBEs. This is determined via an integrated decision-making process.

${ }^{2}$ The references in this column are mostly applicable to LWRs, and hence they are offered as providing useful guidance. In this column, the term "essentially" is used to mean that non-LWR guidance under this process may need to be developed because the referenced documents were developed specifically for LWRs in which risk insights have been "back-fit." Not all references in this column have been formally endorsed by the NRC. 


\subsubsection{TICAP Guidance}

Draft guidance from TICAP provides useful insights into the inclusion of external hazard analysis information and results within a safety analysis report (SAR), including its impact on factors such as SSC classification. Following this guidance, DBHLs are to be specified in Chapter 6, which captures design requirements for SR SSCs. Chapter 5.5 of the SAR documents the NSRST SSCs derived from both the risk significant and DID evaluation criteria. For risk significant NSRST SSCs (RS-NSRST-SSC), each SSC is outlined along with the applicable LBEs, which resulted in the safety classification, as shown in Table 3-3. This includes the PRA Safety Function (PSF), which outlines the functions of the SSCs responsible for preventing or mitigating an unplanned radionuclide release. A similar approach is used for those NSRST SSCs that are required for DID (DID-NSRST-SSCs), as outlined in Table 3-4.

Table 3-3: Example SAR RS-NSRST-SSC Table

\begin{tabular}{l|c|c|c|}
\hline \multicolumn{2}{|c}{ LBES } & $\begin{array}{l}\text { LBE Type (A00, } \\
\text { DBE, or BDBE) }\end{array}$ \\
\hline RS-NSRST-SSC 1 & LBE $_{\mathrm{RS}-1}$ & $?$ & PSF $_{\mathrm{RS}-1}$ \\
\hline RS-NSRST SSC & & $?$ & PSF $_{\mathrm{RS}-2}$ \\
\hline & LBE $_{\mathrm{RS}-2}$ & $\cdots$ & $\ldots$ \\
\hline RS-NSRST SSC & $\cdots$ & $?$ & PSF $_{\mathrm{NS}-\mathrm{N}}$ \\
\hline
\end{tabular}

Table 3-4: Example SAR DID-NSRST-SSC Table

\begin{tabular}{|c|c|c|c|}
\hline NSRST SSC & LBES & $\begin{array}{l}\text { LBE Type (AO0, } \\
\text { DBE, or BDBE) }\end{array}$ & PSF \\
\hline \multirow{4}{*}{ DID-NSRST-SSC $_{1}$} & LBE $_{\text {DID-11 }}$ & $?$ & PSF $_{\text {DID-11 }}$ \\
\hline & $\mathrm{LBE}_{\text {DID-12 }}$ & $?$ & $\mathrm{PSF}_{\mathrm{DID}-12}$ \\
\hline & $\cdots$ & $\ldots$ & $\cdots$ \\
\hline & LBE $_{\text {DID-1n }}$ & $?$ & $\mathrm{PSF}_{\mathrm{DID}-1 \mathrm{n}}$ \\
\hline $\begin{array}{l}\text { Additional DID- } \\
\text { NSRST SSCs... }\end{array}$ & $\cdots$ & $\cdots$ & $\cdots$ \\
\hline
\end{tabular}

This information is followed in Chapter 5.6 of the SAR by the complementary design criteria for the NSRST SSCs, which are derived from the success criteria for the PSFs defined previously. The complementary design criteria for the NSRST SSCs are directly tied to the success criteria established in the PRA for the PSFs responsible for the SSC classification as NSRST. This information is outlined in a table such as Table 3-5. The example analysis of the following subsection will provide an example of how this information could be derived. 
Table 3-5: Example SAR NSRST Complementary Design Criteria Table

\begin{tabular}{|c|c|c|c|}
\hline $\begin{array}{l}\text { NSRST } \\
\text { SSC }\end{array}$ & $\begin{array}{l}\text { PRA Safety } \\
\text { Function }\end{array}$ & PSF Success Criterion & $\begin{array}{c}\text { Complementary Design } \\
\text { Criteria }\end{array}$ \\
\hline \multirow{4}{*}{$\begin{array}{l}\text { NSRST } \\
\mathrm{SSC}_{1}\end{array}$} & $\mathrm{PSF}_{11}$ & Success criterion for $\mathrm{PSF}_{11}$ & Design criterion for $\mathrm{PSF}_{11}$ \\
\hline & $\mathrm{PSF}_{12}$ & Success criterion for $\mathrm{PSF}_{12}$ & Design criterion for $\mathrm{PSF}_{12}$ \\
\hline & $\ldots$ & $\ldots$ & $\ldots$ \\
\hline & $\mathrm{PSF}_{1 \mathrm{n}}$ & Success criterion for $\mathrm{PSF}_{1 \mathrm{n}}$ & Design criterion for $\mathrm{PSF}_{1 \mathrm{n}}$ \\
\hline $\begin{array}{l}\text { Additional } \\
\text { NSRST } \\
\text { SSCs }\end{array}$ & $\ldots$ & $\ldots$ & $\ldots$ \\
\hline
\end{tabular}

Chapter 7 of the SAR outlines the NSRST SSC criteria and capabilities, which includes the specific special treatment requirements and the system description. The special treatment requirements are provided in a table such as Table 3-6, as part of SAR Chapter 7.1. These would align with those special treatments selected with the guidance from Table 3-2. The system description is provided in Chapter 7.2 and should contain the information outlined below:

- Simplified schematic diagram

- Narrative design descriptions that address the design aspects relevant to the performance of the safety significant functions systems including:

$\bigcirc$ the system purpose in the context of supporting the safety significant functions

o significant functional performance-based characteristics in performing safety significant functions

○ system location

- key design features relevant to performance of safety significant functions

o seismic and industry (e.g. ASME, IEEE) code classifications and the design codes applicable to the NSRST SSC,

- description of system operation including a description of the performance modes of operation of the system relevant to the safety significant functions.

$\circ$ Identification of any operator actions needed to implement safety significant functions

- controls and displays needed to support safety significant functions

- logic circuits and interlocks needed to support safety significant functions

- electric power, support systems, and interface requirements needed to support the safety significant functions

- equipment to be qualified for harsh environments as needed to meet SR SSC special treatment requirements defined in Section 7.2 
Table 3-6: Example SAR NSRST Special Treatment Requirements Table

\begin{tabular}{|c|c|c|}
\hline NSRST SSC & $\begin{array}{l}\text { Functional } \\
\text { Description }\end{array}$ & NSRST SSC Special Treatments \\
\hline \multirow{4}{*}{ NSRST SSC $C_{1}$} & \multirow{4}{*}{$\begin{array}{l}\text { Short SSC functional } \\
\text { description for NSRST } \mathrm{SSC}_{1}\end{array}$} & NSRST SSC ${ }_{1}$ Special Treatment No. 1 \\
\hline & & 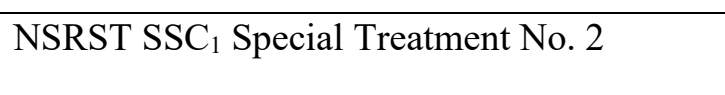 \\
\hline & & $\cdots$ \\
\hline & & NSRST $\mathrm{SSC}_{1}$ Special Treatment No. $\mathrm{n}$ \\
\hline $\begin{array}{l}\text { Additional } \\
\text { NSRST SSCs }\end{array}$ & $\ldots$ & $\cdots$ \\
\hline
\end{tabular}

\subsection{Example Analysis}

A simplified seismic hazard example is presented here to demonstrate the application of the LMP approach for an external hazard analysis. The seismic external hazard was selected, as it is the most common external hazard to be treated using a probabilistic approach. In addition, currents efforts by SwRI, supported by the NRC, on seismic hazard analysis as part of a RIPB approach provide additional guidance on such analyses [4]. However, as described in subsequent sections, the seismic example and the resulting findings are generally applicable to any external hazard addressed through a probabilistic approach.

\subsubsection{PRA Development}

For the example, a representative advanced reactor design is utilized, based on experience with sodium fast reactor concepts. Rather than assessing a complete seismic PRA, a specific seismic initiator was selected to reduce the scope of the example analysis. Seismically-induced loss-ofoffsite-power (S-LOOP) was chosen, as it is likely a generically applicable scenario to most advanced reactor designs.

Before assessing the S-LOOP scenario, an internal events LOOP event tree was constructed for the representative advanced reactor system and is provided in Figure 3-4. For the plant, a SCRAM functionality provides reactivity control. Heat removal is possible through either the balance of plant, operating in a passive mode due to the LOOP event (BOP_P), or a dedicated passive heat removal system $(\mathrm{SHR})^{5}$. Only passive heat removal pathways are considered as many advanced reactor designs do not include diesel generators for the preservation of active heat removal in LOOP scenarios. Significant radionuclide release due to fuel overheating is only possible if both heat removal pathways fail. If this were to occur, a confinement system (CONF) limits radionuclide transport to the environment. However, for confinement to operate successfully at its designed leakrate, it must isolate flowpaths that are typically available during normal operation, such as HVAC pathways. As outlined in Table 3-7, offsite consequences are predicted to occur if radionuclide release from the fuel occurs. However, the magnitude of the release to the environment is greatly

\footnotetext{
${ }^{5}$ The dedicated passive heat removal system is referred to as the "safety" heat removal system in the event tree, due to its designation as SR in subsequent LMP analyses.
} 
reduced if confinement isolation is successful (ES_3). Random system failure probabilities for the event tree are provided in Table 3-8 and are approximated based on current advanced reactor system reliabilities.

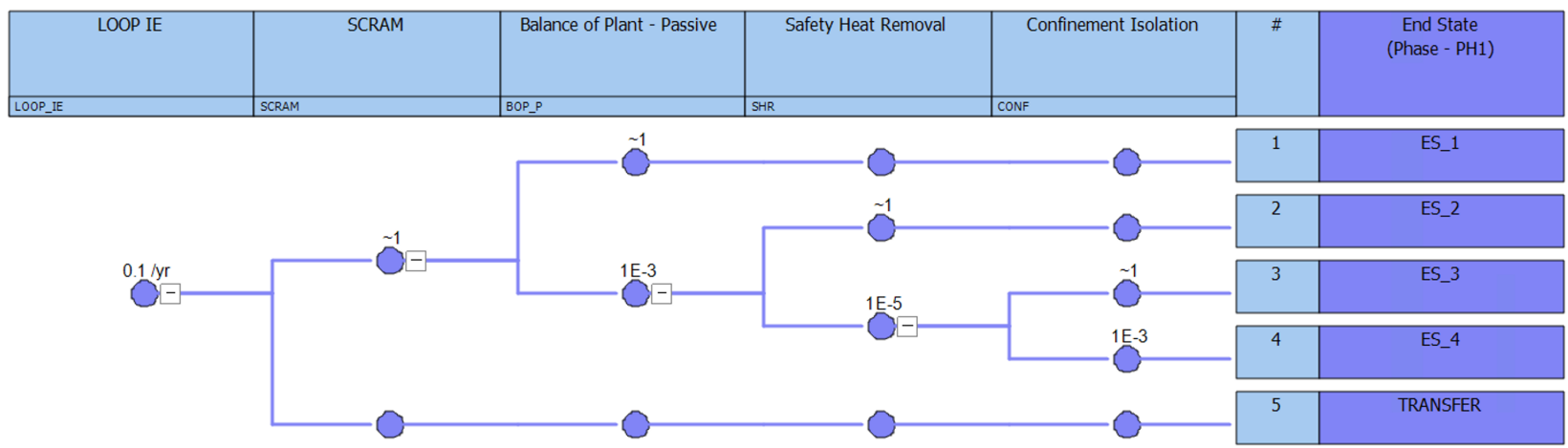

Figure 3-4: Internal Events LOOP Event Tree

Table 3-7: LOOP Event Sequences Offsite Consequence

\begin{tabular}{cccc}
\hline Event & \multicolumn{3}{c}{ Offsite Consequence (rem) } \\
\cline { 2 - 4 } Sequence & $\mathbf{5}^{\text {th }}$ & Mean & $\mathbf{9 5}^{\text {th }}$ \\
\hline ES_1 & 0 & 0 & 0 \\
ES_2 & 0 & 0 & 0 \\
ES_3 & 0.5 & 5 & 15 \\
ES_4 & 35 & 850 & 2,300 \\
\hline
\end{tabular}

Table 3-8: System Random Failure Probabilities

\begin{tabular}{ccc}
\hline System & \multicolumn{2}{c}{ LOOP Failure Probability } \\
\cline { 2 - 3 } & Mean & EF \\
\hline SCRAM & $1 \mathrm{E}-6$ & 5 \\
BOP_P & $1 \mathrm{E}-3$ & 5 \\
SHR & $1 \mathrm{E}-5$ & 5 \\
CONF & $1 \mathrm{E}-3$ & 5 \\
\hline
\end{tabular}

Given the limited scope of this analysis, each event sequence from the LOOP event tree is considered a separate event sequence family (ESF) for subsequent consideration as an LBE in the LMP analysis. In a full PRA, the event sequences could potentially be grouped with other similar event sequences to form ESFs. The ESFs and LBEs are explored further in Section 3.2.2.

For the S-LOOP analysis, the draft SwRI guidance provided in ref [4] was utilized to inform the assessment. Figure 3-5 outlines the RIPB seismic design and LBE selection process from the guidance. Following this approach, seismic hazard information for the site (or for a bounding site) is prepared. Based on preliminary SSC designs, associated fragilities are determined in accordance with seismic design criteria (SDC) and limit states (LS) from applicable codes, such as ASCE 43. The seismic hazard information and SSC fragilities are then used to conduct the seismic PRA and the results are evaluated through the LMP analysis steps outlined in Section 3.1.1. This includes the potential addition of new LBEs, additional SSC classifications, and the evaluation of DID adequacy. In addition, there is a potential for modifications to SSC SDCs or LSs to address the impact on the licensing-related decisions. 


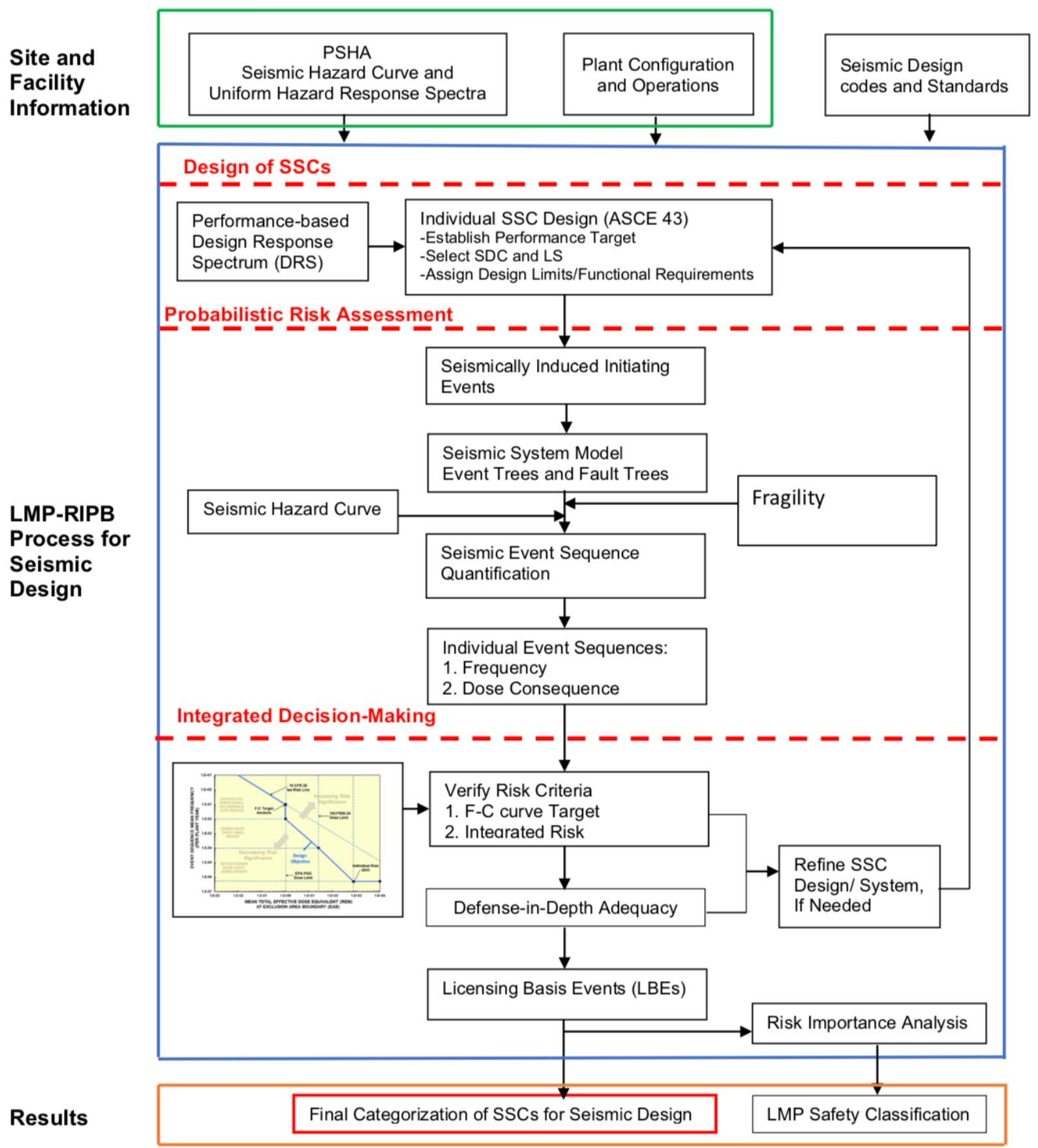

Figure 3-5: RIPB Seismic Design and LBE Selection Process [4]

Following this process, a representative seismic hazard curve was developed for the example plant. The seismic hazard curve family, shown in Figure 3-6, is based on a curve for a nuclear power plant in the Central Eastern United States and represents the PGA $(100 \mathrm{~Hz})$. In the next step of the process, the preliminary seismic design of SSCs is established. There are multiple ways this can be accomplished, and the SwRI process utilizes the performance targets of ASCE 43 to select SDCs and LS. For the example analysis, the fragilities of the plant systems, presented in Table 3-9, were based on preliminary designs of similar systems in advanced reactor concepts. 


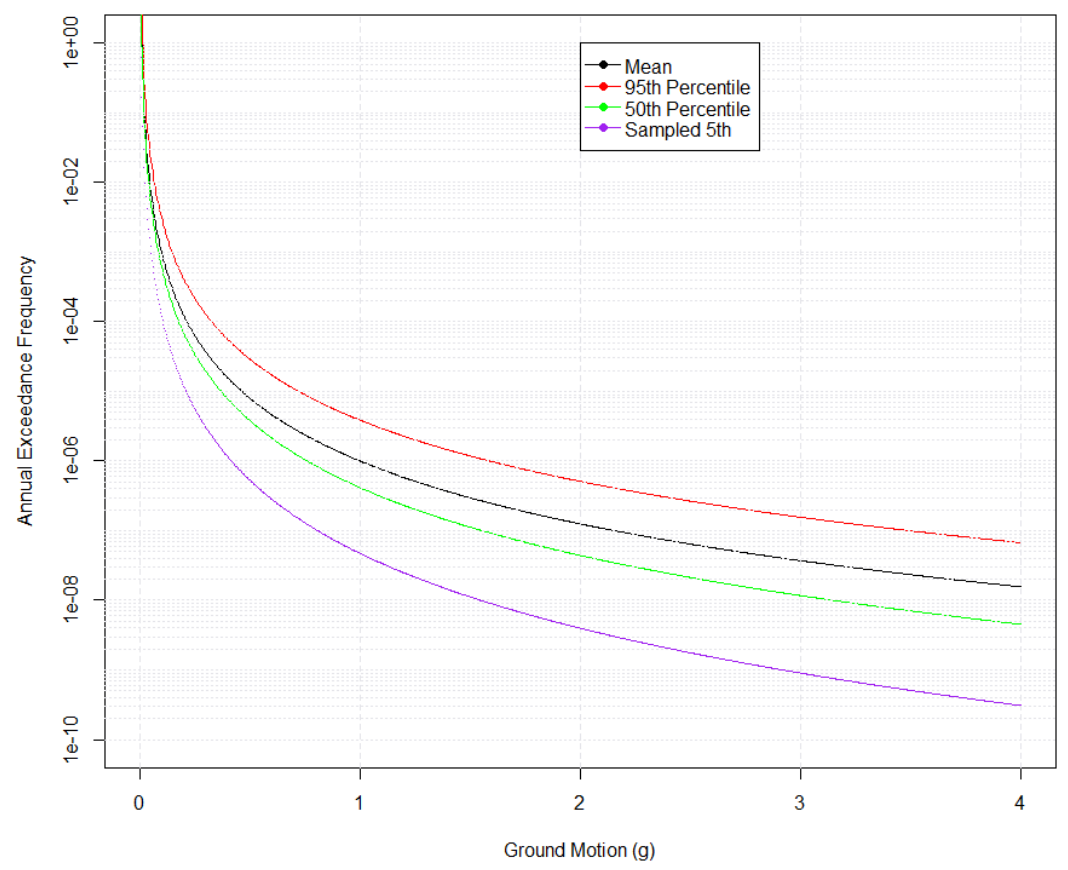

Figure 3-6: Example Seismic Hazard Curve (PGA)

Table 3-9: Component Seismic Fragilities

\begin{tabular}{lccc}
\hline Component & $\mathbf{A}_{\mathbf{m}}(\mathbf{g})$ & $\boldsymbol{\beta}_{\boldsymbol{r}}$ & $\boldsymbol{\beta}_{\boldsymbol{u}}$ \\
& & & \\
\hline Offsite Power (S-LOOP) & 0.3 & 0.3 & 0.3 \\
SCRAM & 3.0 & 0.3 & 0.3 \\
BOP_P & 0.5 & 0.3 & 0.3 \\
SHR & 1.0 & 0.3 & 0.3 \\
CONF & 1.5 & 0.3 & 0.3 \\
\hline
\end{tabular}

For the S-LOOP scenario, the event tree is similar to the internal events LOOP version but with a separation of the seismic initiator and the probability of LOOP, as shown in Figure 3-7. It is important to note that the failure probabilities calculated for use in the S-LOOP event tree include both random and seismically-induced failures. The event sequence identifiers are the same as the internal events LOOP analysis but with the "S_" prefix. The process to calculate the S-LOOP event sequence frequencies and the development of ESFs is detailed in Appendix A, with results discussed in the following subsection.

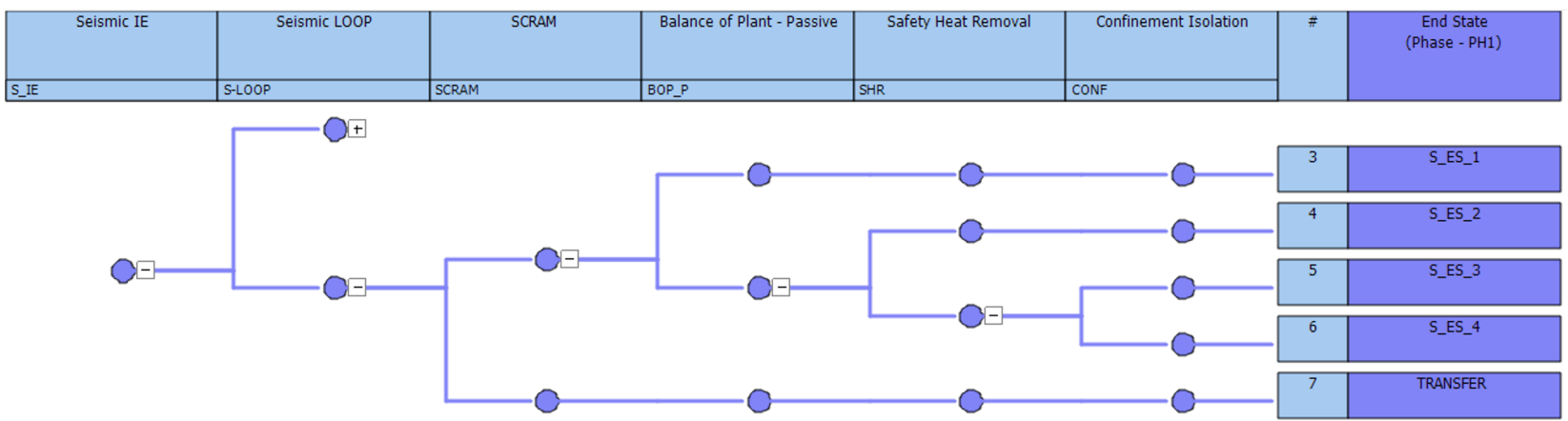

Figure 3-7: S-LOOP Event Tree 


\subsubsection{LBE Analysis and F-C Curve Comparison}

With the information from the LOOP and S-LOOP analyses, the next step is to process the modeled ESFs into applicable LBEs for categorization and comparison to the F-C curve. As previously stated, each of the event sequences in the LOOP event tree was considered a separate ESF for the internal LOOP analysis, resulting in a total of four ESFs. Similarly, for the seismic analysis, each of the four event sequences from the S-LOOP event tree (with accounting for hazard curve/fragility convolution described in Appendix A) was considered a separate ESF.

Figure 3-8 provides the categorization of the ESFs from the internal LOOP event tree. As the results show, ESF_1 falls within the AOO region while ESF_ 2 would be considered a DBE. Due to the high reliability of the heat removal systems, ESF_3 is orders of magnitude below the frequency cutoff for BDBEs, even when considering the $95^{\text {th }}$ percentile of the frequency. The $95^{\text {th }}$ percentile frequency value of ESF_4 is below the frequency cutoff for the plot. These results are summarized in Table 3-10. All four event sequences easily satisfy the consequence target values of the F-C curve. Therefore, the internal LOOP LBEs would not appear to be a motivator for design or SSC modifications.

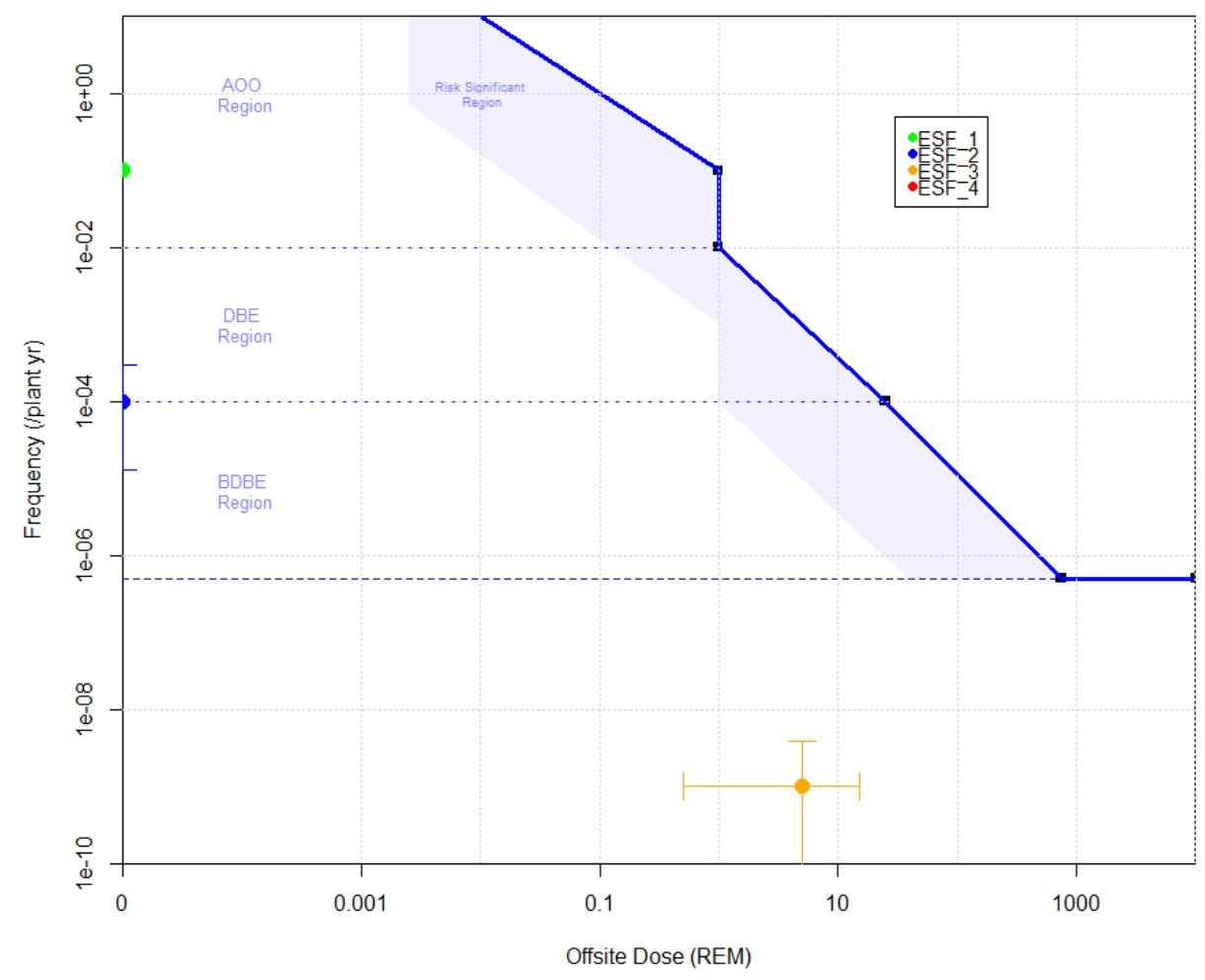

Figure 3-8: Internal Event LOOP ESFs'

\footnotetext{
${ }^{6}$ ESF_ 4 is below the frequency cutoff for the plot.
} 
Table 3-10: Internal Event LOOP ESFs

\begin{tabular}{ccccc}
\hline Event Sequence & \multicolumn{3}{c}{ Frequency $(/ \mathbf{y r})$} & LBE Category \\
\cline { 2 - 4 } Family & $\mathbf{5}^{\text {th }}$ & Mean & $\mathbf{9 5}^{\text {th }}$ & \\
\hline ESF_1 & 0.1 & 0.1 & 0.1 & AOO \\
ESF_2 & $1.3 \mathrm{E}-5$ & $1 \mathrm{E}-4$ & $3.0 \mathrm{E}-3$ & DBE \\
ESF_3 & $4.0 \mathrm{E}-11$ & $1 \mathrm{E}-9$ & $3.8 \mathrm{E}-9$ & N/A \\
ESF_4 & $1.5 \mathrm{E}-14$ & $1 \mathrm{E}-12$ & $4.1 \mathrm{E}-12$ & N/A \\
\hline
\end{tabular}

Given the convolution of the seismic hazard curve and SSC fragilities, the S-LOOP event sequence categorization is more complex. The resulting ESFs from the analysis described in Appendix A are provided in Figure 3-9 and Table 3-11. The $95^{\text {th }}$ frequency of S_ESF_1 would result in it being assessed as a DBE, while S_ESF_2 and S_ESF_3 are located within the BDBE region. Although the mean of S_ESF_4 is below the 5E-7 per year threshold, the $95^{\text {th }}$ percentile of the frequency exceeds this value. Therefore, S_ESF_4 is evaluated as a BDBE.

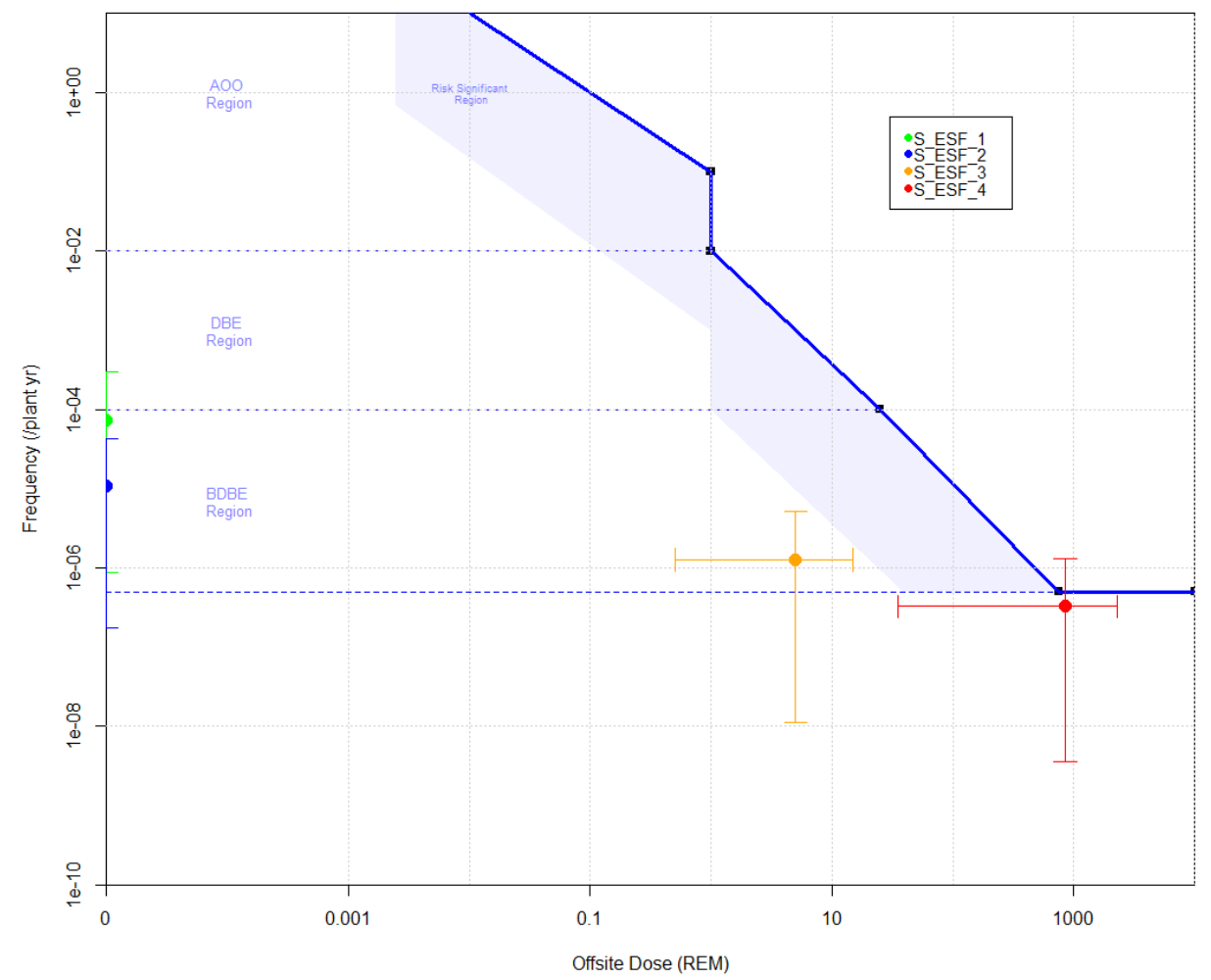

Figure 3-9: S-LOOP ESFs

Table 3-11: S-LOOP ESFs

\begin{tabular}{ccccc}
\hline \multirow{2}{*}{$\begin{array}{c}\text { Event Sequence } \\
\text { Family }\end{array}$} & \multicolumn{3}{c}{ Frequency (/plant yr) } & \multirow{2}{*}{ LBE Category } \\
\cline { 2 - 4 } & $\mathbf{5}^{\text {th }}$ & Mean & $\mathbf{9 5}^{\text {th }}$ & \\
\hline S_ESF_1 & $8.9 \mathrm{E}-7$ & $7.5 \mathrm{E}-5$ & $3.0 \mathrm{E}-4$ & DBE \\
S_ESF_2 & $1.8 \mathrm{E}-7$ & $1.0 \mathrm{E}-5$ & $4.1 \mathrm{E}-5$ & BDBE \\
S_ESF_3 & $1.1 \mathrm{E}-8$ & $1.3 \mathrm{E}-6$ & $5.2 \mathrm{E}-6$ & BDBE \\
S_ESF_4 & $3.7 \mathrm{E}-9$ & $3.3 \mathrm{E}-7$ & $1.4 \mathrm{E}-6$ & BDBE \\
\hline
\end{tabular}


While the results in Figure 3-9 and Table 3-11 provide the results of the S-LOOP analysis, they do not capture how the plant behavior changes with varying levels of ground motion. For the two SLOOP ESFs with non-zero associated doses (S_ESF_3 and S_ESF_4), the event sequence frequency is a tradeoff between the increase in the likelihood of SSC failures due to higher PGA values versus the reduced frequency of the more severe seismic event occurring. Figure 3-10 contains the frequency density function (similar to a probability density function but utilizing the event frequency) for S_ESF_3. As the plot demonstrates, this event sequence has the highest likelihood of occurrence at approximately $0.65 \mathrm{~g}$, with an almost trivial likelihood of occurrence below 0.4g. Similarly, Figure 3-11 contains the same plot for S_ESF_4, which peaks in likelihood at approximately $1.23 \mathrm{~g}$, with a negligible frequency below approximately $0.6 \mathrm{~g}$. Even though a larger ground motion is more likely to result in S_ESF_4, the reduced frequency of the seismic event results in a lower overall frequency.

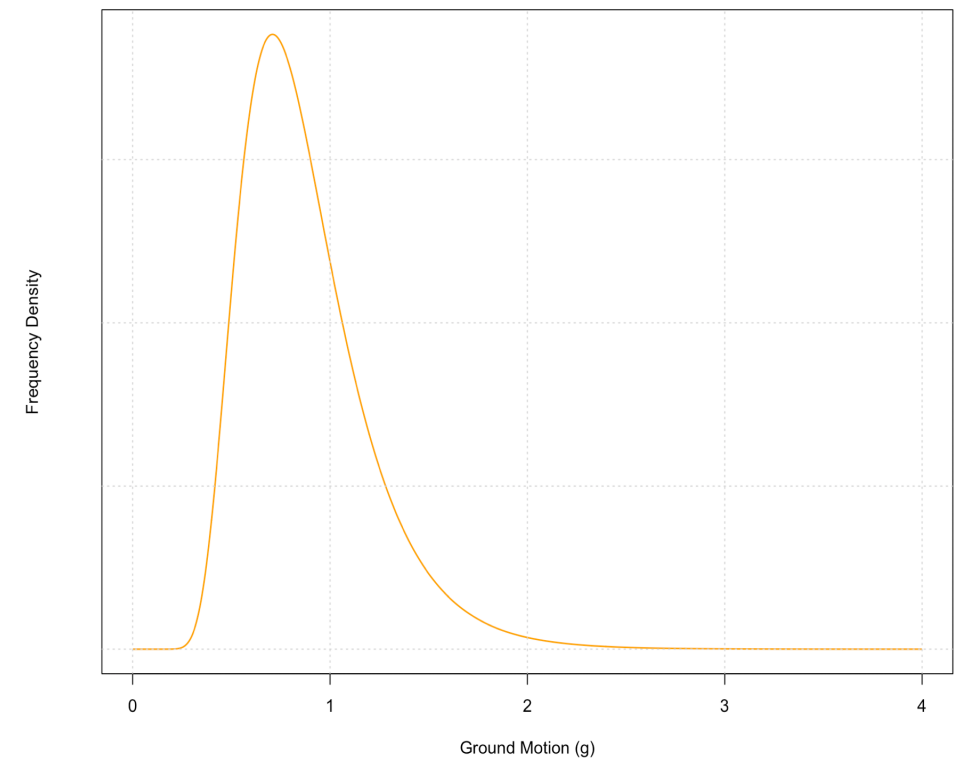

Figure 3-10: Frequency Density of S_ESF_3 versus Ground Motion

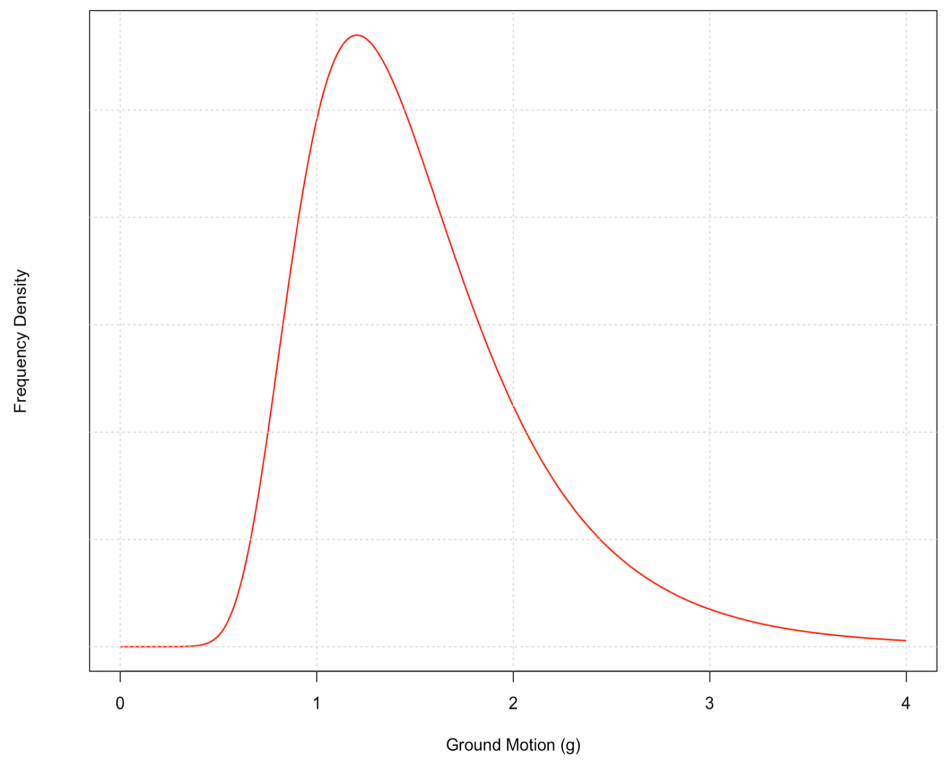

Figure 3-11: Frequency Density of S_ESF_4 versus Ground Motion 
The trend highlighted in the previous plots is also captured by the complementary cumulative distribution function (CCDF) of each S-LOOP ESF shown in Figure 3-12. This plot highlights the change in cumulative ESF frequency with ground motion. In addition, the plot shows at what ground motion level the ESF enters a LBE region based on its frequency. For example, the mean frequency of S_ESF_3 enters the BDBE region at $0.90 \mathrm{~g}$. As mentioned previously, the mean frequency of S_ESF_4 remains below the BDBE threshold. The peak value of each ESF (at ground motion level $0 \mathrm{~g}$ ) is the frequency of the ESF utilized in the LBE analysis, provided in Table 3-11.

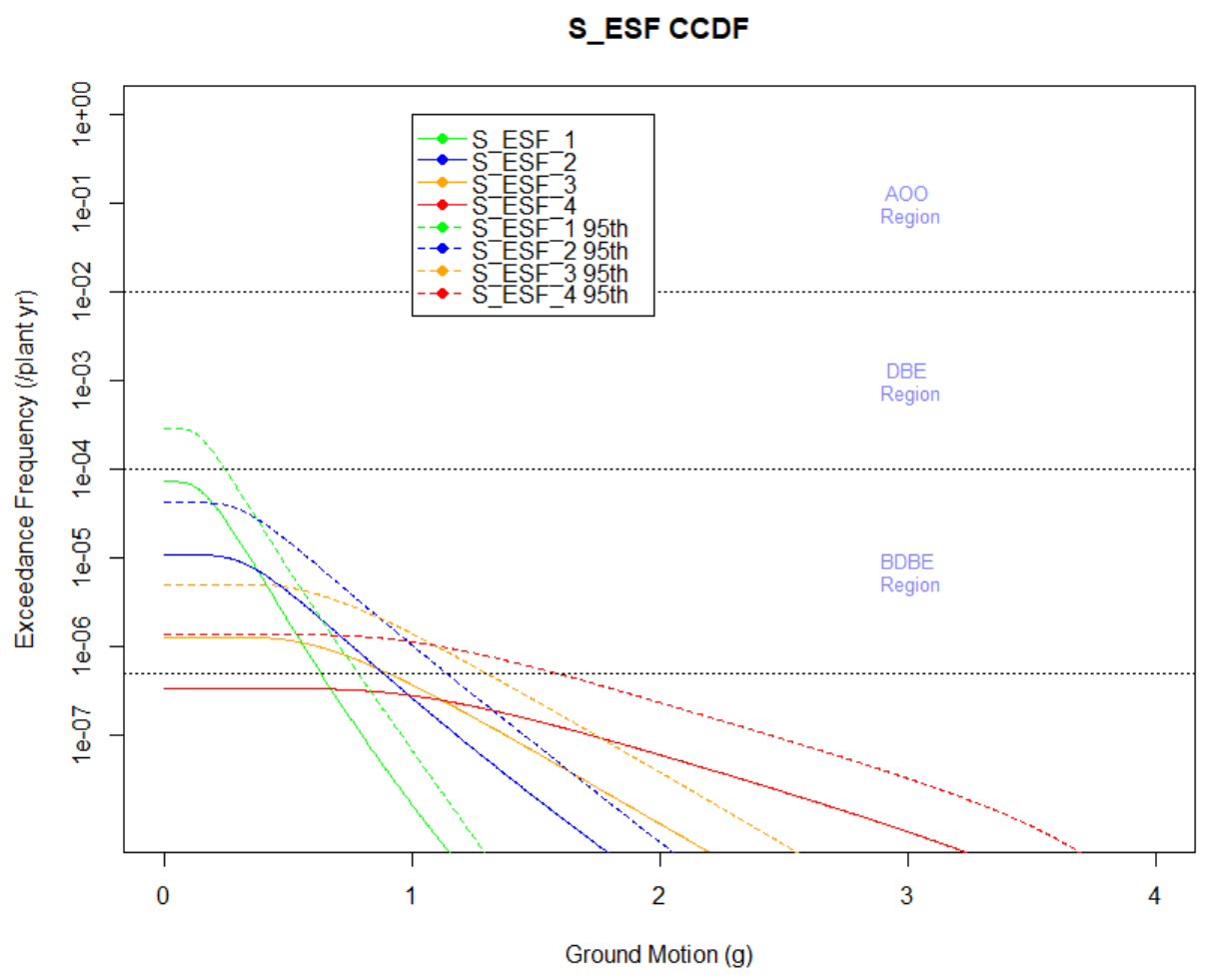

Figure 3-12: S-LOOP ESFs CCDF

The S-LOOP analysis results in four new LBEs, including one (S_ESF_4) that currently exceeds the F-C curve due to the extent of the frequency uncertainty bounds. There are several avenues available to the plant designer to address this LBE, including the following:

- Plant Modifications: The designers may make modifications to the plant design to reduce the frequency or consequence of the LBE of concern such that it no longer exceeds the F$\mathrm{C}$ curve upon re-evaluation. This option is explored further below.

- Uncertainty Reduction: Efforts can be made to reduce the uncertainty associated with the LBE of concern, which may result in the uncertainty bounds no longer exceeding the F-C curve.

- Analysis Refinement: The typically binary nature of PRA event trees may result in simplifying assumptions impacting the resulting frequency or consequence of the LBE of concern. Increased analysis detail may allow further refinement of these characteristics, potentially resulting in the LBE no longer exceeding the F-C curve. 
- Defense-in-Depth Justification: It may be possible to demonstrate the regulatory acceptability of the LBE of concern due to DID protections of the public, such as emergency planning protections or the available time for evacuation.

- Alternative Approaches: Utilization of alternative approaches to demonstrate regulatory acceptability or adequate confidence in the protection of the public (discussed in Section 4).

Potential modification to the plant to address the F-C curve exceedance is discussed further in the remainder of this section. Regarding the other options, reducing uncertainty is likely a difficult task for the LBE of concern, as the uncertainty in frequency is primarily driven by the uncertainty of the seismic hazard curve, which may be irreducible given the state of knowledge. Similarly, analysis refinement may also be difficult, as the behavior of SSCs in a seismically-failed state can be challenging to ascertain. However, these uncertainties may dominate the resulting source term calculation, such as the magnitude of leakage pathways with failed containment isolation.

There may be an avenue to demonstrate regulatory acceptability of the LBE of concern, even with exceedance of the F-C curve. For example, efforts can be made to show that emergency planning protections are in place to protect the public, even with large releases, or that the release timing would provide time for protective actions. However, the nature of large external hazards could make it difficult to demonstrate the effectiveness of such actions, given the likely extent of damage in the area caused by the initiating external event. The final option, to utilize an alternative analysis approach to demonstrate adequate protection of the public, is explored in Section 4.

The option to modify the plant design is investigated here to gain insights into what changes would be necessary to satisfy the F-C curve and for subsequent comparison to the methodologies described in Section 4. S_ESF_4 represents a seismic failure of both heat removal pathways and of confinement isolation. Therefore, there are several potential modifications that could be made to the plant to reduce the frequency or consequence of the ESF. As efforts to reduce the source term may be challenging given seismic failures (as mentioned above), the focus here is on a reduction in the ESF frequency. The frequency of the event sequence depends on both random failure probabilities and the likelihood of seismically-induced failure.

Sensitivity analyses were performed to explore the impact of the random failure probabilities of the SSCs. The results demonstrated that even an order of magnitude reduction in the random failure probabilities for both heat removal systems and confinement isolation results in less than a $5 \%$ reduction in S_ESF_4 frequency. These findings establish that seismically-induced failures dominate the frequency of S_ESF_4. Therefore, the only avenue available to appreciably reduce the frequency of S_ESF_4 is to increase the seismic capacity of one or more SSCs.

Since S_ESF_4 includes confinement isolation failure, the most straightforward approach to reduce frequency would be to increase the capacity of confinement isolation. A simplistic approach is taken for the demonstration here, where the fragility is modified only through an increase in $A_{m}$ with no change in $\beta$ 's. As outlined in Ref [4], a more detailed approach would likely consider modifications to the SDC and LS of the SSC. Following sensitivity analyses, it was found that the $\mathrm{A}_{\mathrm{m}}$ value of confinement isolation would need to be increased from $1.5 \mathrm{~g}$ to $2.25 \mathrm{~g}$ for the $95^{\text {th }}$ 
percentile of S_ESF_4 frequency to move below the 5E-7 per plant year threshold, as shown in Figure 3-13. This modification has a negligible impact on the frequency of the other ESFs.

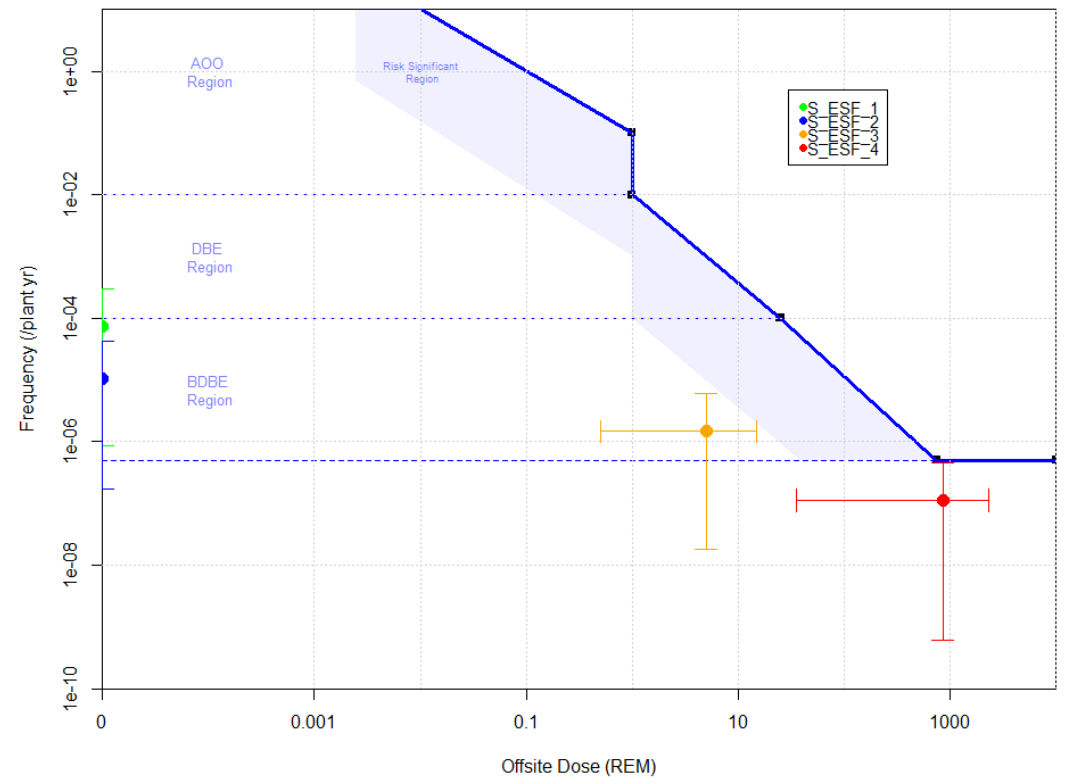

Figure 3-13: S-LOOP ESFs with Increased Confinement Isolation Capacity

An alternative approach would be to increase the seismic capacity of SHR, as it has already been identified as a SR SSC. A similar simplistic approach was taken to explore this possibility, where the $A_{m}$ value of SHR was increased independent of $\beta$ 's. Sensitivity analyses demonstrated that the $\mathrm{A}_{\mathrm{m}}$ value for SHR would need to increase from $1.0 \mathrm{~g}$ to $2.0 \mathrm{~g}$ for the $95^{\text {th }}$ frequency value of S_ESF_4 to remain below the 5E-7 per plant year threshold, as shown in Figure 3-14. The change in SHR capacity also reduces the frequency of S_ESF_3, removing it from the BDBE region. This has additional consequences on SSC classification, discussed in the following subsection.

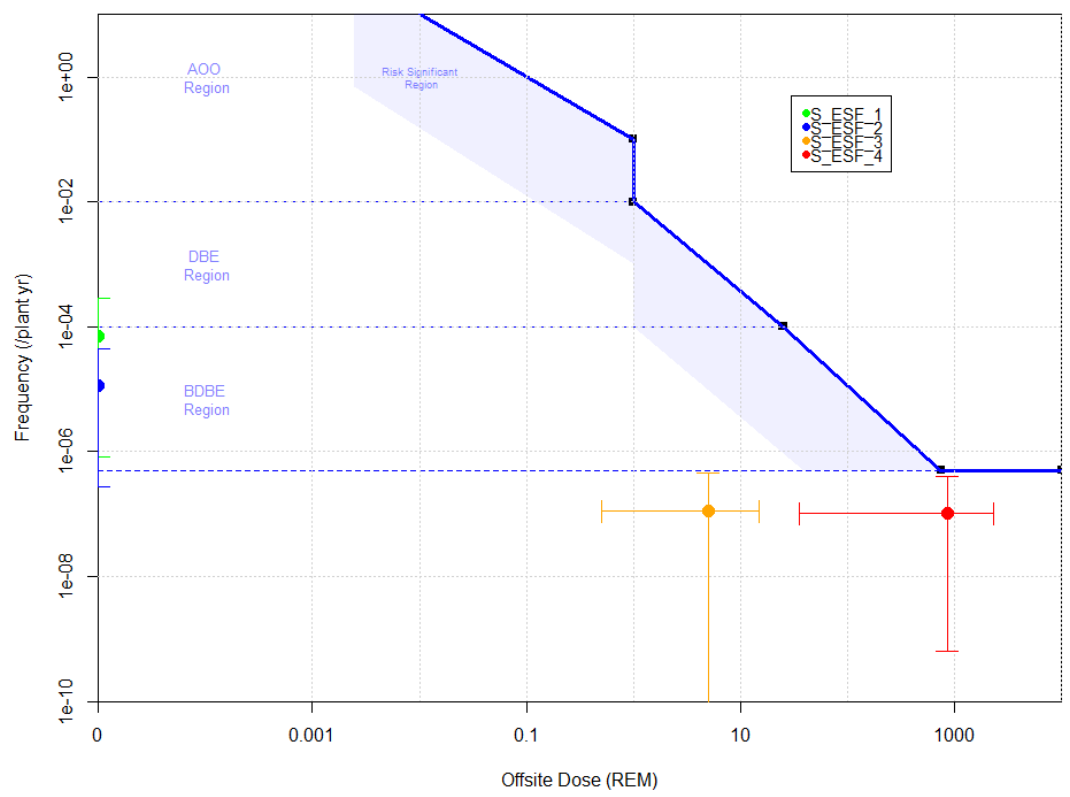

Figure 3-14: S-LOOP ESFs with Increased SHR Capacity 


\subsubsection{SSC Classification}

Following the LMP approach, SSC classification is determined based on a series of deterministic and risk-informed analyses, in addition to DID considerations. Both the internal LOOP and S_LOOP scenarios are assessed here in regard to SSC classification to highlight the importance of the seismic results on licensing decision-making.

\section{Internal LOOP Considerations}

As outlined in Section 3.1.1, SSC classification is performed based on the identified RSFs and the LMP SSC classification criteria. For this example, the internal events LOOP LBEs would result in the identification of two RSFs, reactivity control and heat removal. Based on the following criterion, a DBA would be derived from ESF_2 (a DBE). The DBA version of ESF_2 would have to demonstrate adherence to the 25 rem limits of 10 CFR 50.34 while only crediting SR SSCs.

\section{- Safety-Related:}

- SSCs selected by the designer from the SSCs that are available to perform the RSFs to mitigate the consequences of DBEs to within the LBE F-C Target, and to mitigate DBAs that only rely on the SR SSCs to meet the dose limits of 10 CFR 50.34 using conservative assumptions

While there are multiple avenues available to satisfy this criterion, the most straightforward approach for the current example would be to designate SCRAM and SHR as SR SSCs (this selection was already assumed within the naming of SHR above). There would be no NSRST SSCs based on the internal LOOP LBEs, as ESF_3 and ESF_4 are far below the frequency required for detailed analysis.

\section{S-LOOP Considerations}

Following the F-C curve analysis in the preceding subsection, modification to the capacity of SHR or confinement isolation would move S_ESF 4 below the BDBE frequency threshold. If SHR capacity is improved, then S_ESF_3 also moves below the BDBE region. The following criteria are applicable for SSC classification associated with BDBEs:

\section{- Safety-Related:}

- SSCs selected by the designer and relied on to perform RSFs to prevent the frequency of BDBE with consequences greater than the 10 CFR 50.34 dose limits from increasing into the DBE region and beyond the F-C Target

\section{- Non-Safety-Related with Special Treatment (NSRST):}

- Non-safety-related SSCs relied on to perform risk-significant functions. Risksignificant SSCs are those that perform functions that prevent or mitigate any LBE from exceeding the F-C Target or make significant contributions to the cumulative risk metrics selected for evaluating the total risk from all analyzed LBEs

○ Non-safety-related SSCs relied on to perform functions requiring special treatment for DID adequacy 
Regarding the single SR criterion, the only S-LOOP BDBE with consequence greater than the 10 CFR 50.34 dose limits (25 rem) is S_ESF_4. Sensitivity analyses demonstrated that the capacity of SHR alone is sufficient to prevent the frequency of this LBE from rising to the DBE region. Since SHR is already a SR SSC, there are no additional SR SSCs due to S-LOOP LBEs.

Sensitivity analyses are also required to assess whether the NSRST designation is required for any of the SSCs based on the first NSRST criterion. For each LBE in the BDBE region, analyses are performed to determine whether the SSC removal (i.e., no credit) results in the LBE exceeding the consequence targets. This is the standard risk measure used in PRA of risk achievement (RA), in which a component is assumed not to exist or have failed. For this analysis, the results differ depending on whether the decision to modify the seismic capacity of confinement isolation or SHR was selected.

If confinement isolation capacity was improved, S_ESF_3 remains a BDBE (as shown in Figure 3-13). Therefore, the RA sensitivity analysis results in the findings presented in Table 3-12. Note that the assessment only needs to examine those SSCs that are not already classified as SR, which are the BOP operating in passive mode (BOP_P) and confinement isolation.

\begin{tabular}{cccc}
\multicolumn{2}{c}{ Table 3-12: S-LOOP NSRST Analysis (with CONF Improvement) } \\
\hline BDBE & $\begin{array}{c}\text { Offsite Dose } \\
\text { of LBE }\end{array}$ & $\begin{array}{c}\text { Offsite Dose with Identified } \\
\text { System Removed (rem) }\end{array}$ \\
\cline { 3 - 4 } & (rem) & BOP_P & CONF \\
\hline S_ESF_1 & 0 & 0 & 0 \\
S_ESF_2 & 0 & N/A & 0 \\
S_ESF_3 & 5 & N/A & 850 \\
\hline
\end{tabular}

For both S_ESF_1 and S_ESF_2, no NSRST requirements are necessary since the offsite consequence is still within the target value when either BOP_P or confinement isolation are removed. However, for S_ESF_3, the mean offsite dose increases to 850 rem when confinement isolation is not credited. Figure $3-15$ highlights the S_ESF_3 LBE that encounters this scenario and the impact of not crediting confinement isolation. It is important to note that the S_ESF_3 frequency is $1.3 \mathrm{E}-6$ per plant year or approximately 1 in 800,000 plant years. Based on these findings, confinement isolation would be designated as an NSRST SSC.

Alternatively, if SHR capacity was improved instead of confinement isolation, then only two BDBE LBEs remain (S_ESF_1 and S_ESF_2). Conducting the same RA sensitivity results in the findings in Table 3-13, where no LBEs exceed the F-C curve with SSC removal. Therefore, no SSCs are identified as NSRST based on the RA analysis. 


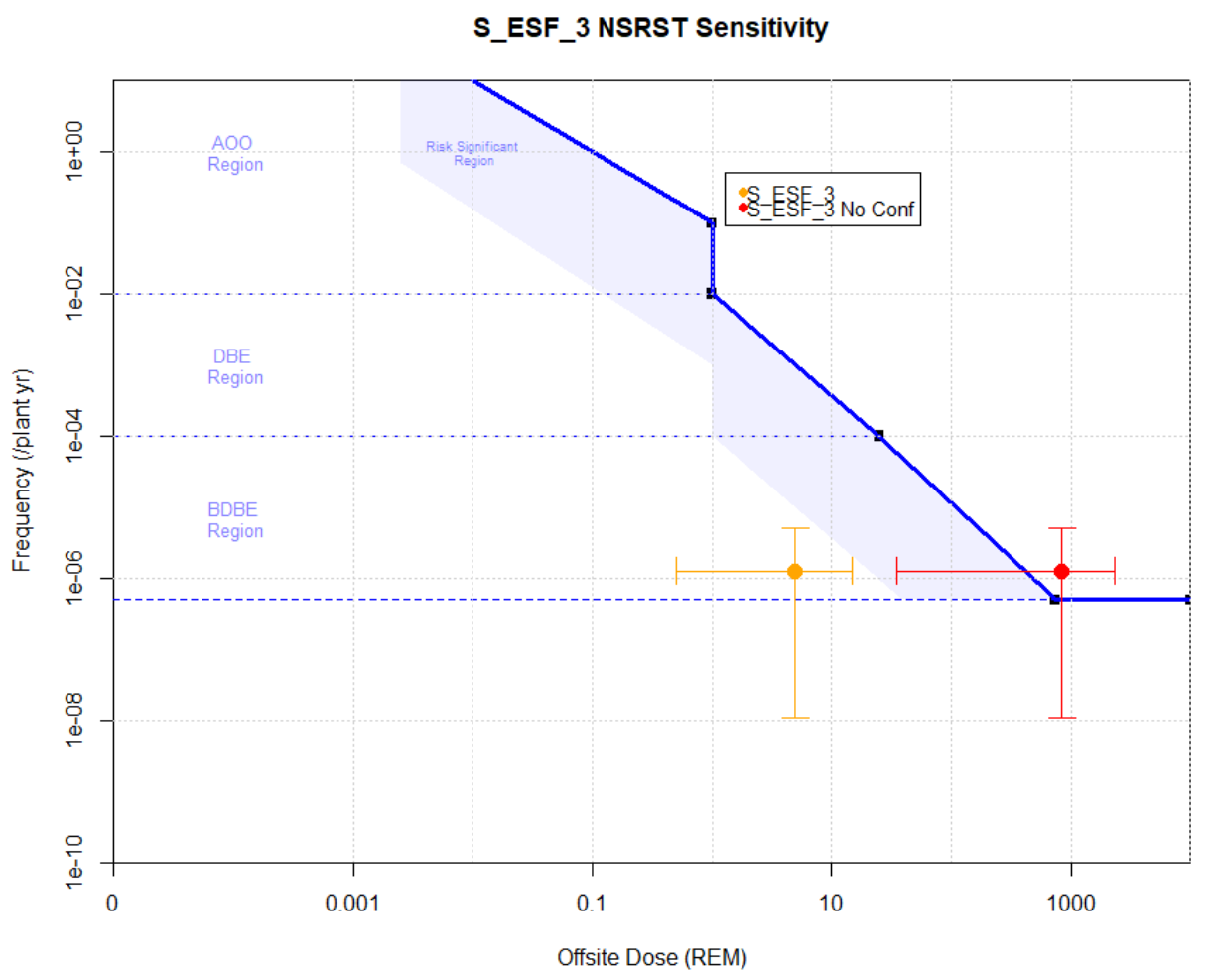

Figure 3-15: NSRST Sensitivity Analysis for S_ESF_3

Table 3-13: S-LOOP NSRST Analysis (with SHR Improvement)

\begin{tabular}{cccc} 
BDBE & $\begin{array}{c}\text { Offsite Dose } \\
\text { of LBEs }\end{array}$ & \multicolumn{2}{c}{$\begin{array}{c}\text { Offsite Dose with Identified } \\
\text { System Removed (rem) }\end{array}$} \\
\cline { 3 - 4 } & (rem) & BOP_P & CONF \\
\hline S_ESF_1 & 0 & 0 & 0 \\
S_ESF_2 & 0 & N/A & 0 \\
\hline
\end{tabular}

Lastly, although S_ESF_4 is no longer formally an LBE (not an AOO, DBE, DBA, or BDBE), assuming sufficient changes to SHR or confinement isolation capacity, it does require consideration given the magnitude of its consequence and proximity to the F-C curve. At the frequency level of S_ESF_4, there are no restrictions on consequence. No additional SSCs are preventing this LBE from increasing in consequence, as S_ESF_4 already represents a failure of both heat removal pathways and confinement isolation. However, the first NSRST criterion described above considers the reliability of systems that are maintaining LBEs within the consequence target. The reliability of other SSCs is ensuring that S_ESF_4 is at a frequency below the BDBE threshold and therefore within the acceptable limits of the consequence target. As demonstrated above, with a reduction in SSC capacity, the frequency of S_ESF_4 would enter the BDBE region and exceed the consequence target. Therefore, special treatments regarding the reliability of confinement isolation would be derived from this ESF.

Table 3-14 summarizes the S-LOOP SSC classification options, depending on the design modification choice from the preceding subsection. Although an improvement in confinement isolation capacity results in S_ESF_4 satisfying the F-C curve, the findings of the SSC 
classification sensitivity analyses results in special treatments on both the performance and reliability of confinement isolation. In contrast, an improvement in SHR capacity would remove the performance special treatment requirements for confinement isolation, as S_ESF_3 (which requires successful confinement isolation) is also removed from the BDBE region. It is important to note that further DID evaluations and considerations as part of the IDP process were not included here and could potentially include other mitigation pathways or SSC classification changes.

Table 3-14: Summary of S-LOOP SSC Classification Options

\begin{tabular}{lll}
\hline Design Modification Option & \multicolumn{2}{c}{ Confinement Isolation Special Treatments } \\
\cline { 2 - 3 } & Performance & Reliability \\
\hline $\begin{array}{l}\text { Confinement Isolation Capacity Change } \\
\text { (1.5g to 2.0g) }\end{array}$ & $\begin{array}{l}\text { Mitigate the consequences } \\
\text { of S_ESF_3 to within the }\end{array}$ & $\begin{array}{l}\text { Maintain the frequency of } \\
\text { S_ESF_4 below 5E-7 per } \\
\text { plant year at the 95 }\end{array}$ \\
& $\begin{array}{l}\text { F-C curve }(\sim 400 \text { rem }) \text { at } \\
\text { the } 95^{\text {th }} \text { percentile }\end{array}$ & $\begin{array}{l}\text { percentile } \\
\text { SHR Capacity Change }\end{array}$ \\
(1.0g to 2.25g) & None & $\begin{array}{l}\text { Maintain the frequency of } \\
\text { S_ESF_4 below 5E-7 per } \\
\text { plant year at the } 95^{\text {th }} \\
\text { percentile }\end{array}$ \\
\hline
\end{tabular}

\subsubsection{SSC Special Treatment Designation}

Utilizing the current TICAP guidance, an attempt was made to further define special treatment requirements for the example analysis, assuming that the confinement isolation design modification was selected. First, the applicable LBEs are identified, and PSFs and PSF success criteria are derived, as described in Table 3-15. For confinement isolation, there is one applicable LBE (S_ESF_3) and one additional ESF that also requires consideration, although not a formal LBE (S_ESF_4), both of which are detailed here.

Table 3-15: Derivation of PSFs, Success Criterion, and Complementary Design Criteria Applicable LBEs PSFs PSF Success Criterion Complementary

\begin{tabular}{llll}
\hline S_ESF_3 & $\begin{array}{l}\text { Prevent radionuclide } \\
\text { migration to the }\end{array}$ & $\begin{array}{l}\text { Radionuclide release from } \\
\text { confinement must be such }\end{array}$ & $\begin{array}{l}\text { Confinement leakage } \\
\text { rate must be }<\mathrm{XX} \text { vol\% } \%\end{array}$ \\
& $\begin{array}{l}\text { acceptable limits for } \\
\text { that offsite doses are }<400\end{array}$ & rem for applicable $\mathrm{LBE}^{1}$ during $\leq 1.3 \mathrm{~g}$ & $\begin{array}{l}\text { per dasmic events. } \\
\text { reisment }\end{array}$
\end{tabular}
applicable LBE

\begin{tabular}{|c|c|c|c|}
\hline S_ESF_4 ${ }^{3}$ & $\begin{array}{l}\text { Reduce the frequency of } \\
\text { the applicable ESF below } \\
\text { the acceptable threshold } \\
\text { for the associated } \\
\text { consequence level }\end{array}$ & $\begin{array}{l}\text { Maintain sufficient } \\
\text { reliability to reduce the } \\
\text { frequency of the applicable } \\
\text { ESF below } 5 \mathrm{E}-7 / \mathrm{yr} \text { (at } 95^{\text {th }} \\
\text { percentile) }\end{array}$ & $\begin{array}{l}\text { Confinement isolation } \\
\text { median fragility must } \\
\text { be } \geq 2.0 \mathrm{~g} \text { (or analogous } \\
\text { SDC/LS level) }\end{array}$ \\
\hline
\end{tabular}

\footnotetext{
${ }^{1}$ The highlighted target dose level is an estimate of the consequence curve based on the frequency of S_ESF_3.

${ }^{2}$ The exact acceptable leakage rate value would be determined based on mechanistic source term and offsite consequence analysis from the PRA and the target dose level.

${ }^{3}$ S_ESF_4 is not a formal LBE, as it is below the BDBE frequency threshold, but does have an impact on confinement reliability requirements based on the NSRST criteria, described in Section 3.2.3.
} 
For S_ESF_3, the PSF for confinement isolation is the retention of radionuclides to within acceptable consequence levels. Although not described in detail in Section 3.2.1, only binary success criteria for confinement isolation were considered within the example PRA, where success was the ability to maintain its design basis leakage rate, which results in a mean offsite dose of 10 rem for S_ESF_3, and failure represents essentially immediate leakage with a mean offsite dose of $850 \mathrm{rem}$. However, the performance of confinement isolation to retain radionuclides is not necessarily binary but could be a spectrum. Therefore, the PSF success criterion for S_ESF_3, outlined in Table 3-15, is the ability to maintain the offsite consequence to within the F-C target value ( $400 \mathrm{rem})$, rather than a default to the design basis leakage rate. The CCDF for S_ESF_3 (provided in Figure 3-12) was examined to determine the appropriate complementary design criteria. It is not necessary for confinement isolation to achieve the PSF success criterion for all seismic scenarios but just those with sufficient frequency to be above the BDBE threshold. The CCDF plot demonstrates that the frequency of S_ESF_3 enters the BDBE range around 1.3g at the $95^{\text {th }}$ percentile. Therefore, the leakage rate of confinement must be able to reduce offsite doses below $\sim 400$ rem for seismic scenarios of $\leq 1.3 \mathrm{~g}$. In addition, in an actual analysis, a specific leakage rate could be derived based on a mechanistic source term and offsite consequence analysis.

For S_ESF_4, the PSF and associated success criterion for confinement focus on sufficient reliability such that the frequency of S_ESF_4 is below the BDBE threshold of 5E-7 per plant year at the $95^{\text {th }}$ percentile value. The design modifications discussed above required an increase in median capacity from 1.5 to $2.0 \mathrm{~g}$ to achieve this goal. As described in Ref [4], varying the SDC or LS of confinement would likely be utilized directly to determine the necessary requirements.

Table 3-16 and Table 3-17 outlines how the PSF, PSF success criteria, and complementary design criteria information could be provided in the SAR based on TICAP guidance.

Table 3-16: Example Confinement Isolation RS-NSRST-SSC SAR Content

\begin{tabular}{|c|c|c|l|}
\hline NSRST SSC & LBE Type & PSF \\
\hline $\begin{array}{c}\text { Confinement } \\
\text { Isolation }\end{array}$ & S_ESF_3 & BDBE & $\begin{array}{l}\text { PSF }_{\text {RS-1: Prevent radionuclide }} \\
\text { migration to the environment beyond } \\
\text { acceptable limits by retaining } \\
\text { radionuclides released from the } \\
\text { reactor vessel. }\end{array}$ \\
\cline { 2 - 4 } & S_ESF_41 & Non-LBE & $\begin{array}{l}\text { PSF } \\
\text { ESF-2: Reduce the frequency of the } \\
\text { the associated consequence level. }\end{array}$ \\
\hline
\end{tabular}

${ }^{1}$ S_ESF 4 is not a formal LBE, as it is below the BDBE frequency threshold, but does have an impact on confinement reliability requirements based on the NSRST criteria, described in Section 3.2.3. 
Table 3-17: Example Confinement NSRST Complementary Design Criteria SAR Content

\begin{tabular}{|c|c|c|c|}
\hline NSRST SSC & $\begin{array}{l}\text { PRA Safety } \\
\text { Function }\end{array}$ & PSF Success Criterion & $\begin{array}{l}\text { Complementary Design } \\
\text { Criteria }\end{array}$ \\
\hline \multirow[t]{2}{*}{$\begin{array}{l}\text { Confinement } \\
\text { Isolation }\end{array}$} & $\mathrm{PSF}_{\mathrm{RS}-1}$ & $\begin{array}{l}\text { The success criterion for } \\
\text { confinement Isolation is the } \\
\text { retention of radionuclides } \\
\text { to within acceptable limits } \\
(\sim 400 \text { rem }) \text { for the } \\
\text { applicable LBE. }\end{array}$ & $\begin{array}{l}\text { Confinement } \text { CDC-1: }_{\text {: During }} \leq 1.3 \mathrm{~g} \\
\text { seismic events, failure of } \\
\text { confinement isolation must be } \\
\text { limited such that the maximum } \\
\text { leakage rate is }<\mathrm{XX} \text { vol\% per } \\
\text { day }^{1} \text {. }\end{array}$ \\
\hline & $\mathrm{PSF}_{\mathrm{RS}-2}$ & $\begin{array}{l}\text { Maintain sufficient } \\
\text { reliability to reduce the } \\
\text { frequency of the associated } \\
\text { ESF below } 5 \mathrm{E}-7 / \mathrm{yr} \text { at } 95^{\text {th }} \\
\text { percentile. }\end{array}$ & $\begin{array}{l}\text { Confinement }_{\text {CDC-2: }} \text { : Confinement } \\
\text { median fragility must be } \geq 2.0 \mathrm{~g} \\
\text { (or analogous SDC/LS level). }\end{array}$ \\
\hline
\end{tabular}

${ }^{1}$ The exact acceptable leakage rate value would be determined based on mechanistic source term and offsite consequence analysis from the PRA.

Before attempting to define special treatment requirements, it's important to review how the assumed design of confinement compares to the designated complementary design criteria. For CDC-1, confinement leakage must be below a certain value (well above the design basis) for seismic events at or below $1.3 \mathrm{~g}$. The necessary reliability of this performance function is not high, as the S_ESF_3 LBE already has a frequency of 1.3E-6 per plant year. In addition, at 1.3g, the assumed fragility of confinement isolation has a mean failure probability of approximately 0.16 . However, confinement isolation does not have to perform at the design basis level. Confinement isolation may be able to achieve CDC-1 even with severe distortion, given the high acceptable consequence level. For example, even with plastic deformation of the structure that could result in door breaches and HVAC penetration bypass avenues occurring, the leakage rate may still be less than the value necessary to satisfy the offsite consequence target. For CDC-2, the fragility assumed for confinement is already within the target range, which is why S_ESF_4 is below the BDBE frequency threshold. The as-built confinement must be in-line with these assumptions to meet CDC-2.

Table 3-18 summarizes a preliminary attempt to select the applicability of the special treatment requirements for confinement. As the table shows, the applicable special treatments focus on the documentation of the complementary design criteria (including analyses justifying the allowable leakage rate and the determination of the designated fragility requirements) and the ability for confinement to meet the criterion, such as the selected SDC/LS level. This would include information demonstrating that the plant was constructed in accordance with the design assumptions utilized in these calculations. The majority of this information would likely be documented as part of a design reliability assurance program (D-RAP), which would cover many of the applicable special treatments in the table. During operation, essentially, the only special treatment is the change control process (including the impact of any updates to the hazard profile), which ensures that changes to the confinement's categorization or complementary design criteria due to plant modifications are properly tracked and addressed. The exact process for determining and implementing such changes is to be explored in future TICAP activities [43]. Due to the nature of confinement and the associated complementary design criteria, in-service testing, monitoring, or inspections may not be necessary. 
Table 3-18: Summary of Applicable Special Treatments for Confinement Isolation Example Special Treatment Category Applicability $\quad$ Reasoning

Document basis for SSC categorization by Integrated Decision-Making Process

Document evaluation of adequacy of special treatment to support SSC categorization

Change control process to monitor performance and manage SSC categorization

Reliability Assurance Program (RAP) including reliability and availability targets for SSCs in performance of PRA Safety Functions

Design Requirements for SSC capability to mitigate challenges reflected in LBEs

Maintenance Program that assures targets for SSC availability and effectiveness of maintenance to meet SSC reliability targets

Licensee Event Reports

User provided Quality Assurance Program for non-safety SSCs

Technical Specifications

Seismic design basis

Pre-service and risk-informed in-service inspections

Pre-service and in-service testing

$\begin{array}{ll}\checkmark & \begin{array}{l}\text { Necessary for documentation of the SSC } \\ \text { classification process. }\end{array} \\ \checkmark & \begin{array}{l}\text { Necessary for justification of applicable } \\ \text { and non-applicable special treatments. }\end{array}\end{array}$

$\checkmark \quad$ Necessary to ensure that confinement categorization does not change over plant lifetime due to modifications or new information.

Necessary for determination of required performance targets (focus on D-RAP aspect), as operational monitoring likely not necessary due to the nature of the complementary design criteria.

Necessary to ensure confinement design meets requirements. Overlaps with DRAP.

$\times \quad$ Due to the nature of confinement and the associated complementary design criteria ${ }^{1}$, performance and condition monitoring should not be necessary or very minimal (beyond change control outlined above).

Necessary but only to the extent it would change confinement categorization or complementary design criteria.

Necessary but limited to D-RAP to provide confidence in calculations deriving complementary design criteria and that the as-built plant meets the design requirements.

$\mathbf{x} \quad$ Not needed due to the nature of confinement and the associated complementary design criteria.

$\checkmark \quad$ Necessary but covered through analyses that would be documented as part of LMP process and D-RAP.

? $\quad$ Pre-service inspections potentially needed but only for verification that confinement was built according to required design requirements.

$\mathbf{x} \quad$ Not needed due to the nature of confinement and the associated complementary design criteria ${ }^{1}$.

\footnotetext{
${ }^{1}$ As the complementary design criteria are focused on confinement performance during severe seismic events, pre-service and in-service testing (such as leak-rate testing) are likely not necessary. Instead, confidence is derived from the calculations demonstrating confinement performance in such scenarios and assurance that confinement was built to the seismic design specifications.
} 
To summarize, based on LMP and TICAP guidance, the required special treatments for confinement isolation can be narrowly tailored ("right-sized") to address only the direct challenges from the applicable LBEs. In this case, this primarily results in the proper documentation of analyses and ensuring that the as-built plant is in accordance with the associated requirements and assumptions. The operational requirements would be constrained to proper accounting of any future changes that may impact confinement performance or change its performance requirements. Utilizing this approach, the resources necessary to assure adequate confidence in the performance of the necessary safety function can be allocated most efficiently and therefore minimized. However, there are still additional resources required to complete this process. The following section will discuss how the level of detail inherent within this process may provide additional benefits in this licensing process.

\subsection{Challenges and Opportunities}

The RIPB approach to external hazard analysis outlined in the previous subsection offers both challenges and opportunities to vendors utilizing the process, which are reviewed here.

\subsubsection{Challenges}

In the example seismic analysis, the plant designer is faced with a decision regarding how to address a very low frequency seismic event that exceeds the F-C curve. Such a finding could require additional analyses or potential plant modifications. Regarding the latter, improving the seismic capacity of the identified SSCs may be a serious challenge. The seismic failure probability may be driven by characteristics of the system that are either costly to improve, impossible to modify without further safety repercussions ${ }^{7}$, or dependent on the performance of other systems or structures (such as the integrity of the building).

Even if a justification can be provided to avoid plant modifications, additional analyses come at the cost of resources and time. Also, as demonstrated, there are further impacts on SSC classification and special treatment designation. The associated special treatment requirements have the potential to result in additional costs or complexity for the assurance of system performance. This could be particularly challenging for the seismic range under consideration, especially once uncertainty is considered.

Given the inherent uncertainty associated with the event sequence in question due to its dependence on the seismic hazard curve estimate, it is debatable whether it represents a genuine threat that should warrant such actions. It is also questionable whether the results of the analysis are of sufficient fidelity (given the uncertainty of the seismic hazard curve) to support the changes in design that were selected for the example analysis.

Although the example analysis focused on seismic events, the challenges encountered may be present for any external hazard treated in a similar probabilistic hazard/fragility-based approach for which there is less historical precedent. This is largely due to several common factors regarding low frequency external events, outlined below:

\footnotetext{
${ }^{7}$ An example is sodium piping in the secondary system of sodium fast reactors, where the thin-walled piping is used to prevent internal thermal stresses during transient scenarios that encounter large changes in sodium temperature.
} 
- Increased Severity of External Hazards with a Low Frequency of Occurrence: Following the LMP framework, event sequences of frequency as low as 5E-7 per plant year $^{8}$ are evaluated in detail for decisions regarding LBE categorization, SSC classification, and DID. At this frequency level, the severity of potential external hazards can be significant, beyond the threshold historically considered for plant design, and below the level of historical data from which to relate frequency of occurrence with hazard loads.

- Increased Uncertainty Associated with External Hazards with a Low Frequency of Occurrence: As the frequency of the external hazard initiators decreases, the uncertainty regarding their severity and frequency typically increases. The uncertainty can be quite large due to several factors, such as the limited quantity of recent regional data due to the rareness of events. In some cases, although it is possible to analyze historic or paleohistoric events, such as floods, to assess the magnitude of low frequency events, the interpretation of these events is not only difficult, but subsequent climatological changes may invalidate their relevance. The LMP approach requires the assessment of ESF frequency at the $95^{\text {th }}$ percentile, which may drive ESFs with very low median frequency but large uncertainty into the BDBE region.

- Initiating Event Dominance on Event Sequence Frequency: With growing severity of external hazard initiators, the conditional failure probability of plant systems approaches one. As a result, the frequency of event sequences with multiple system failures may approach the frequency of the initiating event itself. As the initiator may have large uncertainty regarding its frequency (as detailed in the previous bullet), the subsequent event sequences have similarly large frequency uncertainty, impacting subsequence design and licensing decisions.

- Cliff-Edge Effects: Since the conditional failure probability of plant systems approaches one as the severity of external hazards increases, the failure of a substantial number of SSCs may occur at extreme values of the hazard curve. The exact location of such events in frequency space, which may be greatly uncertain, can result in the need for plant modifications or potentially the inability to utilize a site.

The large magnitude of external hazard severity and uncertainty is inherent with the evaluation of event sequence frequencies at the level of 5E-7 per plant year ( 1 in 2 million years). At such levels, the potential external hazards can be extreme. For example, the seismic hazard curve for the Diablo Canyon Nuclear Power Plant results in a PGA of almost 10g at an annual exceedance frequency of 5E-7 [44]. Similar extreme examples can be found for other hazards, such as flooding, high winds, and volcanism. Such events would cause catastrophic damage to the surrounding area in addition to the nuclear plant, on a level rarely seen in human history.

Based on these factors, the ability of plant designers to use a RIPB approach for the assessment of external hazards may be faced with the following challenges:

\footnotetext{
${ }^{8}$ Event sequences of frequency below $5 \mathrm{E}-7$ per plant year may also require consideration for the identification of cliffedge effects and DID impact, or due to their location within the risk significant region.
} 
- Growing NSRST Requirements from Low Frequency External Events: If multiple external hazards are assessed using a probabilistic approach, there is a potential to introduce a suite of new NSRST SSC requirements based solely on the protection against low frequency external events. This may result in a substantial expansion in the number of SSCs under regulatory consideration, especially for generally passive plants with minimal SR SSCs.

- Lack of External Hazard Analysis Guidance: Many external hazards have historically been evaluated utilizing deterministic, subjectively conservative methods rather than probabilistic approaches. Therefore, detailed guidance on performing probabilistic analyses may not be available. Lack of an experience base in the application of probabilistic methods to these hazards could lead to added uncertainty regarding the obtained results, with a consequence of increased conservatism in any design or licensing decisions. Although the probabilistic/fragility approach developed for seismic analysis can be applied to the analysis of other types of external hazards, there is not the experience base that exists for seismic analysis.

- Lack of Code/Standard Design and Analysis Guidance: While an extensive library of codes and standards exists for the design of SSCs and protection against external events, the severity of the external hazard initiators under consideration may be beyond the scope of available standards. Specifically, attempting to determine the ability of SSCs to perform their required functionality under such extreme conditions may be difficult to ascertain and outside normal design analysis practices.

\subsubsection{Opportunities}

At their core, RIPB licensing approaches like the LMP seek to provide the basis of an affirmative safety case through an exhaustive examination of risk coupled with complementary deterministic evaluations. The process aims to develop a safety strategy that provides reasonable assurance of adequate radiological protection, while being consistent with and appropriate for the identified risks of the plant. As detailed in the preceding sections, to achieve these goals, the LMP process includes an examination of low frequency external events at a level of detail that was generally not considered previously during the licensing process. While there are identified challenges with this approach, the rigor of such analyses can also provide flexibility in the decisions regarding the design and the basis to justify alternatives to historical licensing decisions that were based (at least in part) due to uncertainties regarding these scenarios, as outlined below:

- Detailed Insights of SSC Importance and Requirements: The risk-informed aspect of the approach provides detailed insights into the specific event sequences impacting plant safety. Through this process, the importance of particular SSCs can be determined, and their role within the safety case clarified.

- Ability to "Right-size" Requirements: Since the specific role of SSCs in terms of plant safety can be ascertained, associated requirements can be "right-sized" or developed in an appropriate and consistent manner.

- Basis for Alternatives to Historical Treatments: In the development of reactor regulation, certain deterministic and/or conservative requirements were established as a method to address uncertainties associated with events that were outside the scope of 
detailed analysis. In contrast, the availability of detailed assessments of such events can provide the justification for reducing conservatism.

First, a RIPB approach provides additional insights into plant performance and the role of SSCs that may not be available through purely deterministic or conservative methods. This information is important as it provides a pathway to "right-size" the requirements associated with specific SSCs. In this way, special treatments and other requirements can be narrowly tailored to address only the direct challenges from the applicable event sequences (LBEs). Utilizing this approach, the resources necessary to assure adequate confidence in the performance of the necessary safety function can be allocated most efficiently and therefore minimized. The detailed information provided by the RIPB analyses may also provide flexibility to the plant designer to achieve the safety targets in multiple ways (such as the alternative SSC capacity cases and special treatment scenarios explored in Sections 3.2.2 and 3.2.3).

Second, as highlighted in Section 2.1, in the history of LWR licensing, the AEC placed great confidence in the ability of a robust containment to withstand both internal and external threats. Although subsequent events challenged this assumption, the inclusion of a robust containment structure has remained a key feature of large LWR designs. However, many non-LWR designs are now pursuing a functional containment strategy that foregoes a large, reinforced building. The ability of a functional containment approach to provide adequate protection against external events will be an important consideration in future licensing submittals. Demonstrating that concepts such as below-grade siting, passive plant response, and multiple radionuclide barriers can maintain offsite consequences below the target values, even for external events of low frequency, is a strong confirmation of the functional containment strategy and justifies the elimination of a large, reinforced building.

Similarly, non-LWR licensing submittals are also likely to propose site sizes and emergency planning zones (EPZs) significantly different from historical LWR precedent. The LMP process was developed to aid in the decision-making regarding these topics, with the NRC also pursuing RIPB EPZ sizing guidance [45]. Both large site sizes and EPZs were strategies to ensure adequate protection of the public in the presence of the uncertainties associated with initial reactor licensing efforts. One of the most direct examples is 10 CFR 100.21 (Non-seismic siting criteria), which requires the reactor site "be located away from densely populated centers." While an avenue for accepting alternative sites is available, it is dependent on such factors as a site's "superior seismic characteristics." The detailed assessment of the risk of external events may present an avenue to justify alternatives approaches that provide similar or greater levels of protection.

Many other licensing-related decisions could benefit from the insights and confidence that come from the detailed assessment of external events. From decisions regarding plant staffing and operational flexibility to the need for severe accident mitigation design alternatives (SAMDAs), the external event analyses as part of the LMP can help ensure a "right-sized" approach is selected and alleviate the need for potentially unnecessary conservatisms. 


\section{Performance-Based Margins Assessment}

The external hazards analysis described in Section 3.2 focused on a RIPB approach to guide licensing decision-making. However, as described in Section 2.3, current regulatory guidance regarding beyond design basis seismic evaluation depends primarily on a performance-based, seismic margins analysis utilizing HCLPF at a multiplier of the SSE. In this section, such a performance-based approach is examined as a complement to the RIPB approach in Section 3.

\subsection{PRA-Based Seismic Margins Analysis}

\subsubsection{Background}

As detailed in Section 2.3, SECY-93-087, the accompanying SRM, and DC/COL-ISG-020 laid the foundation for the current NRC-accepted approach to beyond design basis seismic evaluation for new reactors. In this approach, the plant-level HCLPF capacity, expressed in terms of the PGA, is assessed. Following a PRA-based seismic margins approach, the plant-level HCLPF value is compared to $167 \%$ of the SSE acceleration (derived from either the CSDRS or GMRS, following the guidance of DC/COL-ISG-020). Attempting to utilize an analogous approach for advanced reactors introduces several challenges, outlined below:

- SSE Selection: The current application of DC/COL-ISG-020 utilizes the SSE ground motion as the basis for the PRA-based margins analysis, with guidance on the determination of the SSE for new reactor licensees available in RG 1.208. However, the LMP approach does not explicitly utilize a SSE in the decision-making process but instead identifies DBHLs. As stated in RG 1.233, traditional NRC-approved methods or alternative approaches can be utilized to select DBHLs, although alternative approaches will be reviewed on a case-by-case basis [3]. In addition, guidance from SwRI on RIPB seismic analysis utilizes ASCE 43-05 to determine SSC-specific design basis ground motion [4].

- CDF Analog: The current application of DC/COL-ISG-020 for LWRs focuses on event sequences that could potentially lead to core damage (or containment failure), with CDF used for plant-level HCLPF analyses. However, advanced reactors generally do not use CDF given its limited applicability. The LMP process uses offsite dose directly, and a new metric or threshold based on offsite dose is likely necessary.

First, DC/COL-ISG-020 utilizes the SSE as the foundation for the PRA-based margins assessment, with the plant-level HCLPF compared to $167 \%$ of the SSE PGA. Regulatory guidance is available regarding the selection of a SSE for new reactor licensees. The methodology outlined in RG 1.165 utilized a median hazard frequency of 1E-5 per year to develop a representative hazard-consistent SSE. RG 1.208 has now replaced this document and uses the ASCE 43-05 concept of a performance goal $\left(P_{F}\right)$ of 1E-5 for the determination of a GMRS, which can be utilized as the site-specific SSE. In contrast, the LMP approach does not explicitly utilize a SSE for seismic hazard analyses, but DBHLs are identified instead (as outlined in Section 3.1.1). Current TICAP guidance identifies DBHLs based on hazard frequencies of 1E-4 per plant year, with the exact statistical metric yet to 
be specified. RG 1.233 further notes that DBHLs can be selected using traditional NRC-approved methods or alternative approaches, however, alternative approaches will be reviewed on a case-bycase basis [3]. In addition, the RIPB seismic guidance from SwRI utilizes ASCE 43-05 to develop SSC-specific design basis ground motion depending on the necessary $P_{F}$ for the system.

Although the seismic DBHL would appear to be a natural surrogate for the SSE in the PRA-based margins approach, if applied as a supplement to the LMP method, the seismic DBHL level could vary depending on the approach selected by the vendor for its derivation. Instead, the approach for SSE determination in RG 1.208 could be used for the selection of the ground motion value utilized in the PRA-based margins approach, while the LMP approach and methods such as ASCE 43-05 would be applied to determine the SDC and design basis ground motion for specific SSCs. In this way, the application of the PRA-based margins approach is consistent with the guidance in DC/COL-ISG-020, but the flexibility of a RIPB SSC design approach is retained.

The second issue centers on the proper consequence metric to utilize if the PRA-based margins approach is applied for an advanced reactor. Core damage is not applicable for certain advanced reactor designs, such as those with liquid fuel. Even for advanced reactors with solid fuel, core damage is often a poor surrogate for offsite consequence. Large early release is not quantitatively defined for LWRs, which makes it difficult to apply to advanced reactor concepts. It is also based on concerns regarding a very large release that could occur during the timeframe of evacuation while people are in an unsheltered condition. Since the LMP approach primarily relies on offsite dose as the consequence metric of interest, an analogous metric for advanced reactors should also utilize offsite dose. With the LMP approach, design basis hazards (and the associated DBHL) are evaluated against a 25 rem offsite dose limit. Given that the PRA-based margins approach discussed here is inherently in the beyond design basis category or below and associated with a hazard magnitude greater than the DBHL, the consequence metric should be at a value greater than 25 rem for consistency. Likely the most appropriate choice of consequence metric would be the potential for large release of such magnitude to potentially result in early health effects. Such a metric would therefore be located in the region of hundreds of rem offsite dose. A value of 350 to 500 rem (at the threshold of early fatality ${ }^{9}$ ) would also assure compliance with the safety goal limit for early fatalities [47].

\subsubsection{Example}

To further explore the PRA-based seismic margins approach, the example seismic analysis detailed in Section 3.2 was evaluated utilizing the recommended options for implementation. First, an analogous SSE PGA value was selected based on the hazard curve shown in Figure 3-6. This is a simplification of the actual process for SSE determination, as only a PGA value was selected, and the complete response spectrum (CSDRS or GMRS) was not developed. The guidance from RG 1.208 was utilized to determine a SSE PGA. First, PGAs were found from the hazard curves at annual exceedance frequencies of 1E-4 and 1E-5, as presented in Table 4-1. The GMRS for the

\footnotetext{
${ }^{9}$ The range of $350-500$ rem is the $\mathrm{LD}_{50 / 30}$ with no medical intervention [47].
} 
PGA $(100 \mathrm{~Hz})$ is then found according to Eq. 11, where UHRS is the mean PGA at 1E-4 exceedance frequency. The DF is determined according to Eqs. 2 and 3, where $A_{R}$ is based on the difference between the mean PGA values at exceedance frequencies of $1 \mathrm{E}-4$ and $1 \mathrm{E}-5$. This factor provides information regarding the slope of the hazard curve. Using the values from Table 4-1, a GMRS of $0.239 \mathrm{~g}$ was calculated, as shown in Eq. 4. It is multiplying this value by 1.67 that results in $0.399 \mathrm{~g}$ in Eq. 5. This value is slightly higher than if the mean 1E-4 exceedance frequency value would have been used directly (resulting in $0.361 \mathrm{~g}$ ) but significantly lower than if the mean or median 1E5 exceedance frequency value would have been used (resulting in $0.775 \mathrm{~g}$ or $0.618 \mathrm{~g}$ ).

Table 4-1: Seismic Hazard Curve Key Values

\begin{tabular}{lccc}
\hline $\begin{array}{l}\text { Exceedance Frequency } \\
\text { (/plant year) }\end{array}$ & \multicolumn{3}{c}{ PGA } \\
\cline { 2 - 4 } 1E-4 & $\mathbf{5 0}^{\text {th }}$ & Mean & $\mathbf{9 5}^{\text {th }}$ \\
$1 \mathrm{E}-5$ & 0.179 & 0.216 & 0.326 \\
\hline
\end{tabular}

$$
G M R S=\text { mean } 1 \mathrm{E}-4 \text { UHRS } \times D F
$$

Eq. 1

$$
D F=\max \left[1.0,0.6\left(\mathrm{~A}_{\mathrm{R}}\right)^{0.8}\right]
$$

$$
A_{R}=\frac{\text { mean } 1 \mathrm{E}-5 \text { UHRS }}{\text { mean } 1 \mathrm{E}-4 \text { UHRS }}
$$

$$
\begin{aligned}
& \text { GMRS }=0.216 \times\left(0.6 \times\left(\frac{0.464}{0.216}\right)^{0.8}\right) \\
& G M R S=0.239 g
\end{aligned}
$$

$$
1.67 \times G M R S=0.399 g
$$

Eq. 5

Based on the prior discussion regarding an appropriate consequence metric for the analysis, only S_ESF_4 of the example analysis involves an offsite dose of sufficient magnitude to be generally considered a large release. Therefore, the analysis here focuses on the sequence-level HCLPF value of S_ESF_4. However, the HCLPF of S_ESF_3 is also determined for additional insights. If a complete plant PRA were available, the plant-level HCLPF could be assessed, as opposed to a sequence-based value, consistent with the guidance in DC/COL-ISG-020. Also, as discussed in Section 3.2.2, since the base case for S_ESF_4 exceeded the F-C curve when using the LMP approach, the PRA-based margins approach presented here may provide an alternative means of demonstrating an adequate level of safety. 
To complete the HCLPF analysis, the event sequence logic of S_ESF_4 was defined to develop an event sequence fragility. As shown in Eq. 6, the event sequence includes SCRAM success, followed by failure of both heat removal systems and confinement isolation, where $P$ is the probability of SSC failure. The LOOP top event was not included in the logic, given its negligible contribution due to its low seismic capacity.

$$
\left(1-P_{S C R A M}\right) \times P_{B O P \_P} \times P_{S H R} \times P_{C O N F} \quad \text { Eq. } 6
$$

To calculate the S_ESF 4 event sequence fragility ${ }^{10}$, the applicable PGA range $(0-4 \mathrm{~g})^{11}$ was discretized into 1,000 bins, and the failure probabilities for each SSC were calculated. The fragility curve was derived two ways: including and excluding random failures. Such an approach is suggested in ref [38] to identify the contribution of seismically-induced and random failures. 10,000 Monte Carlo random samples of the SSC fragilities were utilized to develop the distribution of the fragility curve.

Figure 4-1 presents the resulting S_ESF_4 fragility curve family for the base case analysis when including random failures, and Figure 4-2 shows the analogous results without the inclusion of random failures. Both plots also identify the HCLPF value based at 0.05 of the $95^{\text {th }}$ percentile curve. As the results show, the inclusion of random failure has very little impact on the resulting HCLPF values given the generally high reliability of the SSCs in terms of random failure. The fragility curves decrease in probability at high PGA values due to the inclusion of the SCRAM success term in the event sequence logic. SCRAM failure becomes more likely at high PGA levels, which reduces the probability of the S ESF 4 event sequence. However, for the transfer event tree, which was not included in this study, considering events in which there is a failure to scram, the consequences of the associated event sequences could be of similar severity to S_ESF_4.

As demonstrated by Figure 4-1, the HCLPF value for S_ESF_4 is significantly above the 1.67 times SSE value $(0.746 \mathrm{~g}$ versus $0.399 \mathrm{~g})$. Therefore, on a sequence-level HCLPF-basis, the plant would satisfy the requirements of DC/COL-ISG-020 with no further modifications to SHR or confinement isolation. This conclusion differs from the result of the RIPB analysis in Section 3.2, where the base case of S_ESF_4 exceeded the F-C curve.

10 Although DC/COL-ISG-020 permits the "min-max" approach for the margins assessment, ref [38] recommends direct fragility curve convolution when possible to avoid the potential limitations of the min-max approach.

${ }^{11}$ Ground motion levels above $4 \mathrm{~g}$ have negligible impact on the results given their low frequency of occurrence for the selected hazard curve. 


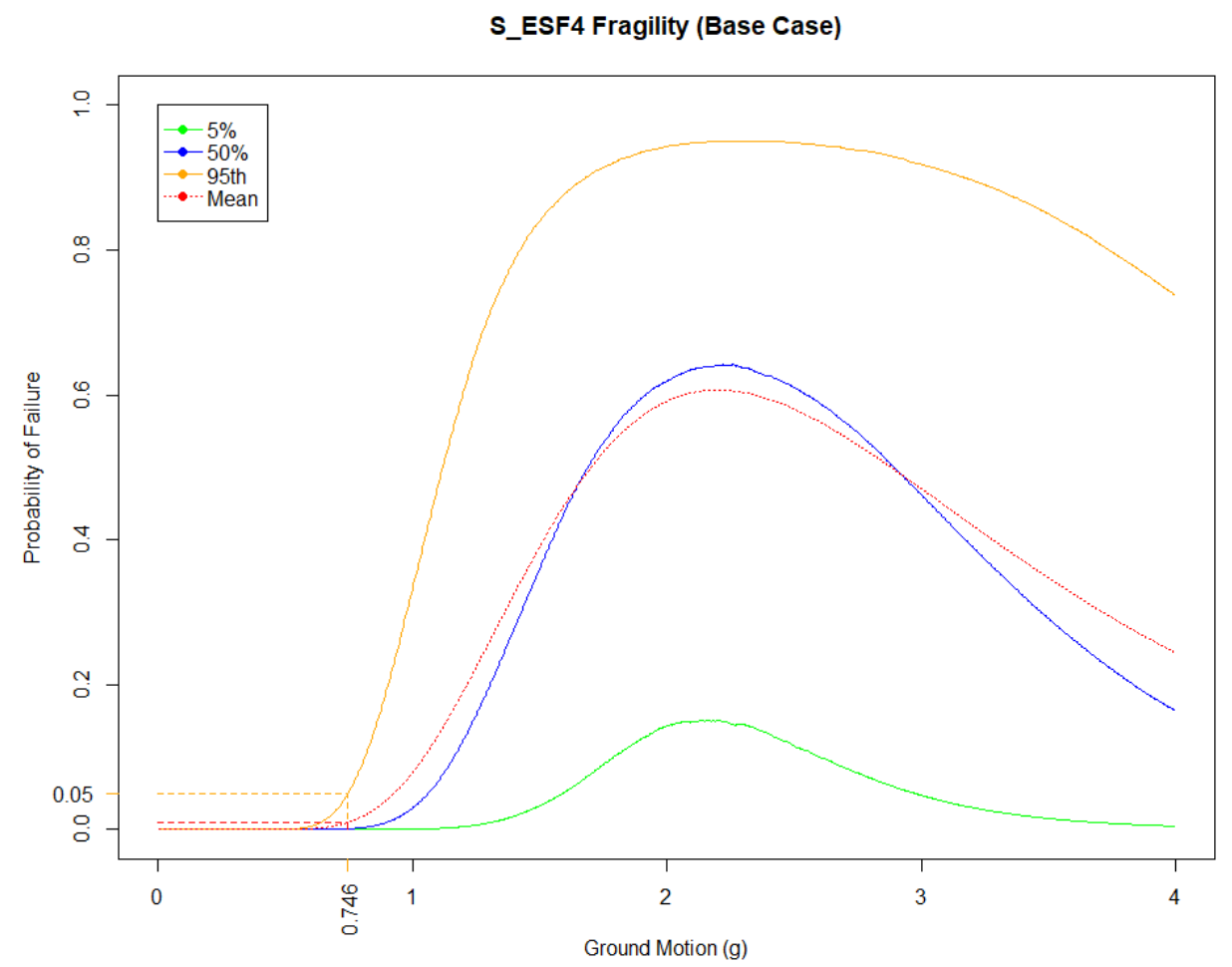

Figure 4-1: S_ESF_4 Sequence-Level Fragility, including Random Failures

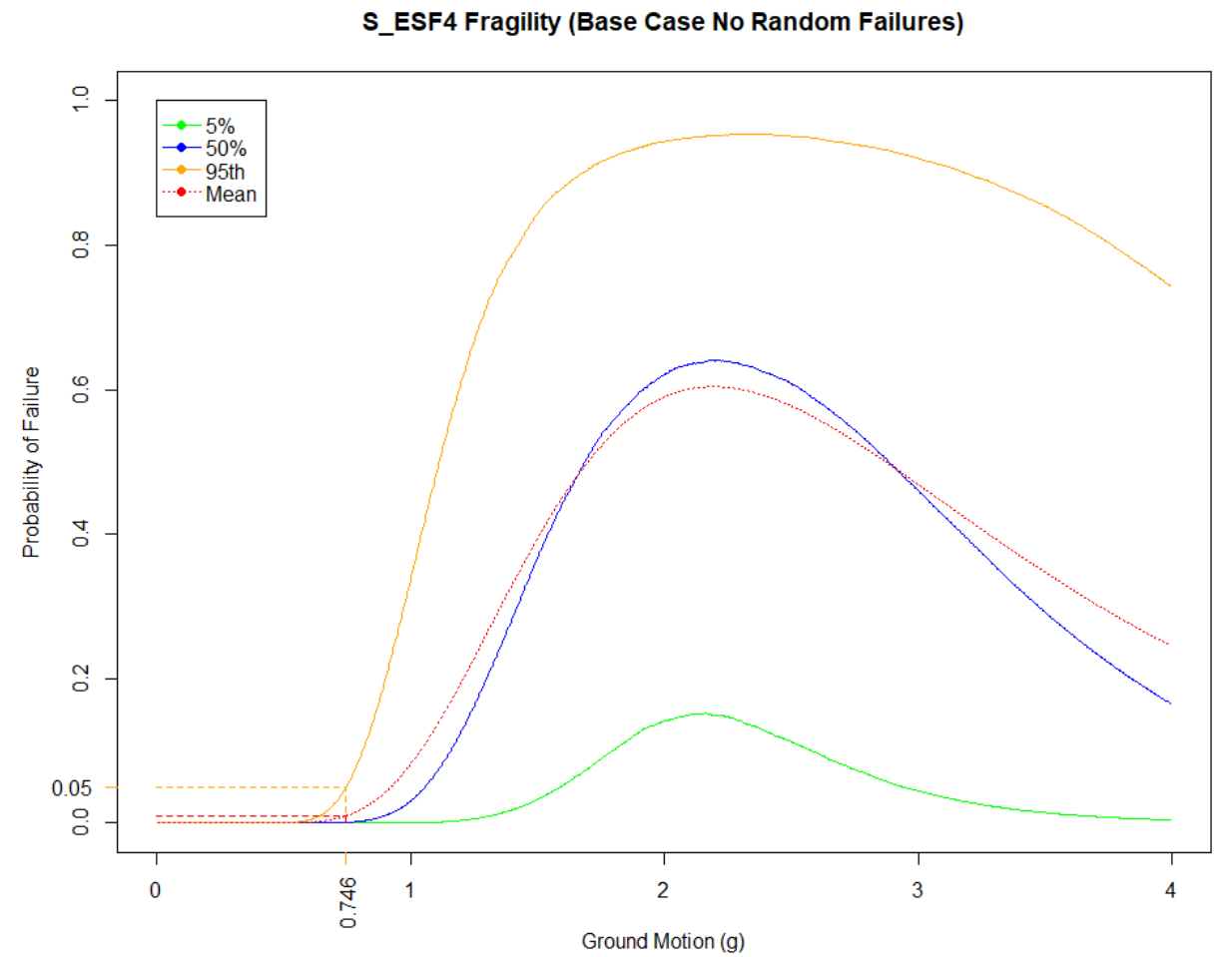

Figure 4-2: S_ESF_4 Sequence-Level Fragility, without Random Failures 
Since DC/COL-ISG-020 also includes core damage scenarios in the HCLPF analysis, S_ESF_3 was also evaluated. Using the same process described above for S_ESF_4, the fragility curve for S_ESF_3 shown in Figure 4-3 was developed based on Eq. 7. The resulting HCLPF value of 0.436g would also satisfy the 1.67 times SSE requirement, implying that further modifications or analysis would not be necessary (for this particular case) even if a more conservative consequence metric were selected.

$$
\left(1-P_{S C R A M}\right) \times P_{B O P \_P} \times P_{S H R} \times\left(1-P_{C O N F}\right)
$$

Eq. 7

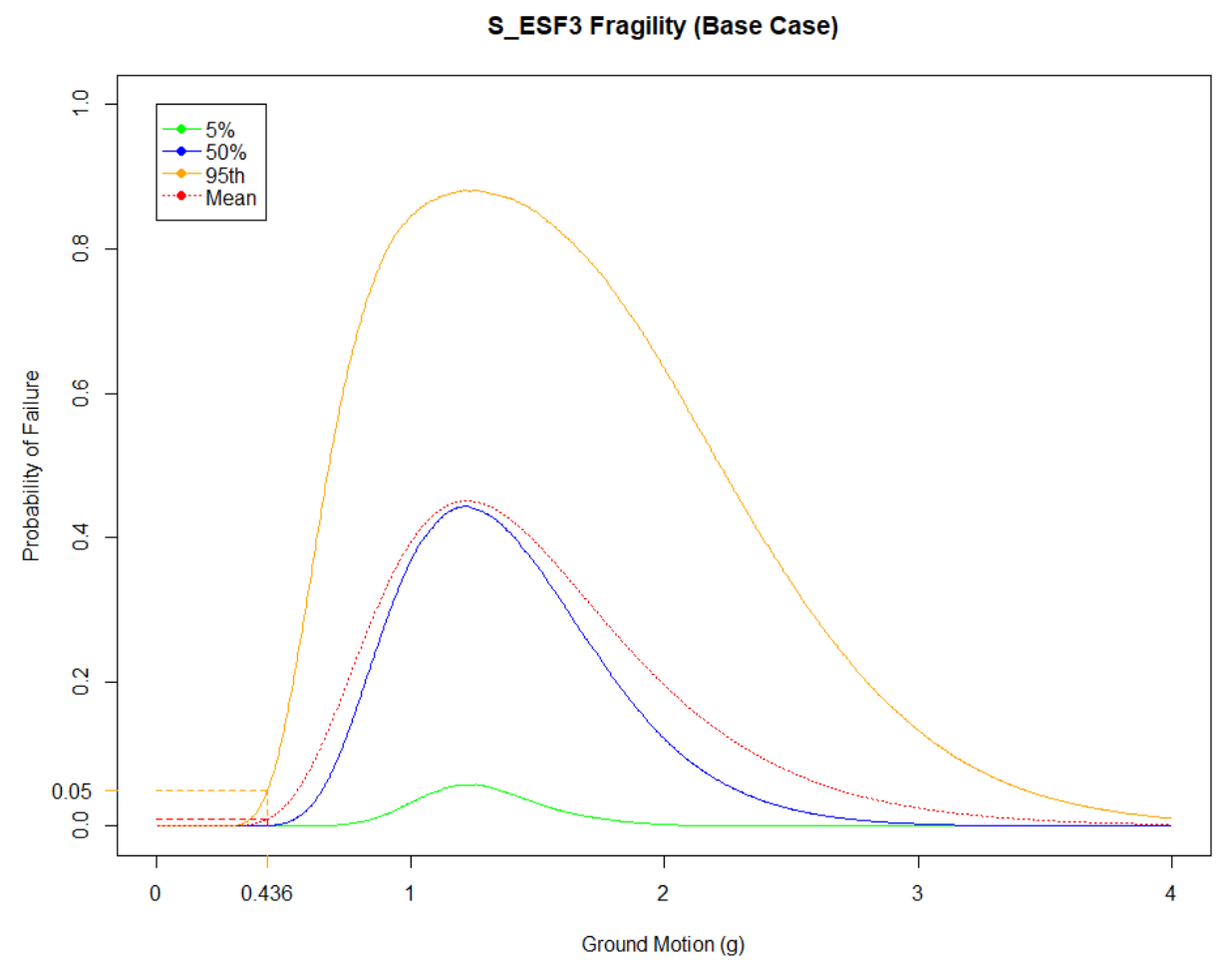

Figure 4-3: S_ESF_3 Sequence-Level Fragility, including Random Failures

\subsection{Challenges and Opportunities}

The implementation of the performance-based PRA-based seismic margins approach presents both challenges and opportunities for use in conjunction with the RIPB methods described in Section 3.

\subsubsection{Challenges}

The exploration and demonstration of a PRA-based seismic margins approach identified several key challenges, outlined below:

- Appropriate Consequence Metric: Given the limited applicability of CDF for advanced reactors, additional development is necessary to identify an appropriate consequence metric for the analysis of beyond design basis external events. Development must also include consideration of consistency with the consequence limit of the DBHLs in the LMP framework. 
- Design Basis Level Consistency: DC/COL-ISG-020 utilizes the current performancebased approach for SSE determination outlined in RG 1.208 as the foundation of the PRAbased margin analysis. LMP does not directly use SSE but instead establishes DBHLs. Given that multiple approaches are available for DBHL selection, there may be inconsistencies if the DBHL is utilized as the basis of the PRA-based margins assessment.

- Differing Conclusions: Further consideration is necessary regarding how to address usecases where differing conclusions may be reached regarding design performance depending on implementation of a PRA-based margins approach versus a RIPB method.

- Applicability to Other Hazards: A goal of advanced reactor licensing pathway development should be an attempt to create a more consistent and uniform approach to external hazards analysis when compared to current regulatory practice for LWRs. Additional consideration is warranted regarding how a similar PRA-based margins approach could be utilized for other external hazards.

First, there are two open questions regarding the implementation of a PRA-based margins approach for advanced reactors. These include the determination of the appropriate consequence metric for use in the analysis, given a lack of CDF, and also the establishment of a ground motion level (and multiplier there-of) for the analysis. Regarding consequence metrics, DC/COL-ISG-020 requires the consideration of CDF and containment failures. However, core damage may not be applicable or may be a poor surrogate for offsite consequence for advanced reactor designs. The concept of a "large release" in the hundreds of rem is likely the best pathway to maintain consistency with DBHL limits $(25 \mathrm{rem})$ but requires additional consideration and clarification regarding DC/COLISG-020 requirements. Similarly, the direct use of the seismic DBHL as the basis for the PRAbased margins assessment may introduce inconsistencies, given that multiple avenues are available for its selection. Instead, the utilization of RG 1.208 to select the ground motion level used as the basis of the PRA-based margin assessment would maintain consistency with current NRC guidance and allow the seismic design basis of individual SSCs to be determined separately, using the LMP approach and associated guidance.

A major open question is how to properly address situations where alternative approaches result in differing conclusions. As the example analysis presented in this report demonstrated, the application of the RIPB approach indicated that additional actions were necessary (whether analyses or design modifications) to address an exceedance of the F-C curve. In contrast, the same design easily satisfied the criteria of the PRA-based seismic margins approach for the same hazard curve. How the approaches can be utilized in a complementary manner to support the establishment of an affirmative safety case requires further consideration.

Lastly, in an effort to support consistent and uniform approaches to the analysis of external hazards (to the extent possible), the applicability of the PRA-based margins approach or similar method to other external hazards should be explored. There are potential complications if the PRA-based margins approach is applied in an identical fashion to other hazards that have established limits on their severity regardless of frequency. However, these challenges could potentially be addressed through the details regarding the implementation of the approach. 


\subsubsection{Opportunities}

Several key benefits were identified during exploration and demonstration of the PRA-based margins approach, outlined below:

- Reduced Dependency on the Low Frequency Range of the Hazard Curve: The greatest benefit of the PRA-based seismic margins approach is that the basis of the analysis is not dependent on the low frequency area of the seismic hazard curve, where confidence in the estimates is reduced. Instead, the evaluation is conducted utilizing information from the hazard curve at frequency values better supported with data and analysis.

- Maintains Detailed Event Sequence Insights: The utilization of a PRA-based margins approach retains many of the detailed insights of a RIPB approach through the use of sequence-level analyses. The importance of individual SSCs can still be ascertained through analysis of the sequence-level fragility curves.

- Complementary Analysis: The PRA-based margins approach may offer an alternative pathway to demonstrate regulatory compliance for event sequences identified through RIPB analyses. In this way, the margins approach is one of the options available to justify the associated licensing decision-making in a similar fashion to the sensitivity analyses presented in Section 3.2.3.

The most significant benefit of the application of the PRA-based margins approach is that there is a reduced dependency on the low frequency range of the hazard curve. As highlighted in 3.3.1, there can be substantial uncertainty associated with the hazard curve at low frequencies, in addition to diminished confidence. The uncertainty and subjectivity of the estimates can dominate the analyses and potentially lead to questionable licensing decision-making. The PRA-based margins approach utilizes values of the hazard curve at a frequency range where confidence is generally higher due to the data and analyses supporting the assessment.

Utilization of a PRA-based margins approach, as was conducted here, also retains the insights obtained from the RIPB analysis concerning important event sequences and SSCs. The impact of specific SSCs can be determined from the sequence-level fragility curves, and the effect of both random and hazard-induced failures can be found. Therefore, the designer retains flexibility in potential modifications and can still derive educated special treatment requirements.

Finally, as implemented here, the PRA-based margins approach could be utilized not as an alternative to the RIPB approach but as a tool within the methodology. In the example analysis, an exceedance of the F-C curve occurred primarily due to uncertainty regarding the hazard curve at low frequency values. Through the PRA-based seismic margins assessment, it could be demonstrated that there is likely ample margin in the design and that subsequent modifications or increases in SSC capacity were not warranted. 


\section{Findings, Recommendations, and Next Steps}

\subsection{Key Findings}

This report summarizes preliminary findings regarding the regulatory treatment of low frequency external events as part of an advanced reactor RIPB framework. The focus of this effort was centered on advanced reactor designs that contain sufficient radionuclide inventory and are sited at locations with sufficient external hazard threat to require detailed probabilistic external hazard analysis. To further understand the implementation of a RIPB approach for such cases, a simplified example seismic hazard analysis was performed following available guidance from the LMP and TICAP. Such an approach was found to be feasible and offered insights into plant performance that could be utilized to inform key licensing decisions and tailor SSC requirements. In addition, the detailed treatment of external events of low frequency also provides justification for the removal of historic conservatisms, which were primarily aimed to address uncertainties regarding such scenarios. However, the detailed probabilistic treatment of low frequency external events also introduces potential challenges due to the inherent uncertainty associated with external events of long return periods.

The probabilistic approach to the assessment of external hazards requires a convolution of the hazard curve and fragilities of the SSCs within the plant. For the seismic example presented here, the increasing uncertainty regarding the estimated hazard curve at low frequencies $(<1 \mathrm{E}-4$ per plant year) resulted in significant uncertainty associated with several low frequency event sequences. The findings of the analysis, primarily driven by the uncertainty in the hazard curve, could potentially result in the need for additional analyses or plants modifications. It is unclear whether such actions would be justified in terms of actual plant risk reduction, given the low frequency of the events and uncertain nature of the results.

As a possible avenue for demonstrating regulatory acceptability of such scenarios, a PRA-based seismic margins approach was assessed, which is the current NRC-approved methodology for the examination of beyond design basis seismic events for new reactors. Through this approach, the dependence of the analysis on the low frequency portion of the hazard curve is removed, but the insights regarding event sequences and SSC importance are retained. The example analysis demonstrated adequate margin for the design (for this specific example) and could potentially be used to alleviate the need for further analysis or plant modifications. The PRA-based margins approach is not without challenges, however, as there are open questions regarding the details of its implementation, and potential solutions were explored in this work.

\subsection{Recommendations}

Based on the findings of the evaluations and analyses presented here, several recommendations have been established to assist the development and application of RIPB licensing frameworks. This includes a central recommendation regarding the use of a PRA-based margins assessment for the analysis of low frequency external events, with supporting recommendations regarding its implementation. 
- Central Recommendation: As part of the LMP framework, consider the potential use of a PRA-based margins approach as one of the complementary tools available for demonstrating the regulatory acceptability of low frequency external event sequences.

○ Reasoning: As detailed in Section 3.2.2, there are many avenues available to the plant designer to demonstrate the regulatory acceptability of specific LBEs. A PRA-based margins approach can be a useful additional tool for the assessment of certain low frequency external event LBEs. The PRA-based margins approach alleviates the dependence on the low frequency range of the hazard curve, where confidence in the estimates is low and uncertainty is large. The approach is also consistent with current regulatory guidance for new reactor licensing. The margins assessment utilizes the PRA developed as part of the LMP process and can be applied to specific event sequences of interest. The central benefits of a RIPB approach are retained, such as the ability to determine the importance of specific events, SSCs, and uncertainties, and to tailor SSC requirements. In addition, all the information and insights from the probabilistic LMP process are preserved.

- Supporting Recommendation \#1: Establish an appropriate consequence metric for use as part of a PRA-based margins analysis that is consistent with existing aspects of the LMP method. The consequence metric should utilize offsite dose as the parameter of interest and represent a magnitude of release similar to the historical concept of "large" release.

- Reasoning: Current regulatory guidance on the application of a PRA-based margins approach utilizes the consequence metric of CDF, which is generally not applicable for non-LWRs. In contrast, the LMP approach uses offsite dose directly as the central consequence metric. Similarly, LMP has a consequence threshold of 25 rem offsite dose for design basis hazard levels (DBHLs). As low frequency external events analyses are inherently beyond design basis, the consequence threshold should be greater than $25 \mathrm{rem}$. An appropriate consequence metric should generally align with the historical concept of "large" release, although a consensus quantitative value has not been established. The use of the $\mathrm{LD}_{50 / 30}$ dose, ranging from 350 to 500 rem [47], would likely provide the key insights necessary from the analysis and also demonstrate compliance with the early fatality safety goal.

- Supporting Recommendation \#2: The methodology outlined in RG 1.208 for SSE determination is an acceptable approach for the selection of the ground motion value (PGA) to be used as the basis of the PRA-based margins approach.

- Reasoning: The implementation of the PRA-based margins assessment in DC/COL-ISG-020 utilizes the SSE determined by RG 1.208 as the foundation of the analysis. If a PRA-based margins approach is used as part of LMP, the same RG 1.208 methodology should be adopted for the determination of the reference ground motion (PGA). The method in RG 1.208 is performance-based and analogous to that of ASCE 43-05. In addition, use of this approach maintains consistency with current NRC guidance but retains the ability to specify the seismic design basis for individual SSCs separately through the LMP process and associated RIPB guidance. 


\subsection{Next Steps}

Based on the findings and recommendations, several follow-on activities are recommended to further support the adoption of a RIPB licensing framework for advanced reactors and provide additional clarity to vendors pursuing such avenues:

- Detailed Demonstration Analysis: To supplement the simplified example provided here, collaboration with a non-LWR vendor to perform a detailed external events analysis for a selected site (or sites) would provide additional insights regarding the implementation of a PRA-based margins assessment for select events in support of a RIPB framework.

- Applicability to Non-Seismic Hazards: The current work has focused on seismic evaluations, given the availability of guidance and importance to plant risk. However, the potential application of the PRA-based margins approach described here to other external hazards as part of a RIPB framework requires additional research to identify the relevant hazard-specific criteria and address potential challenges.

- Coordination with Code/Standard Bodies: As potential challenges with the current code/standard basis are identified, collaborate with the authoring bodies to identify resolution pathways or guidance that are consistent with the intent of the LMP process and analyses.

- Continued Coordination with Industry/LMP/TICAP and Engagement with Part 53 Drafting Efforts: To the extent possible, foster the adoption of consistent and appropriate approaches for advanced reactor external hazard analysis through interaction with RIPB development stakeholders. 


\section{Bibliography}

[1] D. Gardner, "Letter from Kairos Power to the ASME/ANS Joint Committee on Nuclear Risk Management: Need for External Events Screening Criteria for Risk-Informed Applications Supporting Advanced Reactor Designs," KP-MEMO-000035, 2020.

[2] American Society of Mechanical Engineers (ASME)/American Nuclear Society (ANS), "Probabilistic Risk Assessment for Advanced Non-Light Water Reactor Nuclear Power Plants," ANSI/ASME/ANS RA-S-1.4-2021.

[3] U.S. Nuclear Regulatory Commission, "Guidance for a Technology-Inclusive, RiskInformed, and Performance-Based Methodology to Inform the Licensing Basis and Content of Applications for Licenses, Certifications, and Approvals for Non-Light-Water Reactors," RG 1.233, 2020.

[4] N. Chokshi, R. Budnitz, M. Ravindra, B. Dasgupta, and J. Stamatakos, "A Proposed Alternative Risk-Informed and Performance-Based Regulatory Framework for Seismic Safety at NRC Regulated Facilities - Task 3 (DRAFT)," 2020.

[5] National Academy of Sciences, "Lessons Learned from the Fukushima Nuclear Accident for Improving Safety of U.S. Nuclear Plants," 2014.

[6] U.S. Nuclear Regulatory Commission, "Design Basis Floods for Nuclear Power Plants," Regulatory Guide 1.59, 1973.

[7] G. T. Mazuzan and J. S. Walker, "Controlling the Atom, the Beginnings of Nuclear Regulation 1946-1962," NUREG-1610, 1997.

[8] U.S. Atomic Energy Commission, "Theoretical Possibilities and Consequences of Major Accidents in Large Nuclear Power Plants, A Study of Possible Consequences of Certain Assumed Accidents, Theoretically Possible but Highly Improbable, Were to Occur in Large Nuclear Power Plants," WASH-740, 1957.

[9] J. DiNunno, R. E. Baker, F. D. Anderson, and R. L. Waterfield, "Calculation of Distance Factors for Power and Test Reactor Sites," TID-14844, 1962.

[10] J. D. Stevenson, "Historical Development of the Seismic Requirements for Construction of Nuclear Power Plants in the U.S. and Worldwide and their Current Impact on Cost and Safety," Transactions of the 17th International Conference on Structural Mechanics in Reactor Technology (SMIRT 17), 2003.

[11]U.S. Atomic Energy Commission, "Nuclear Reactors and Earthquakes," TID-1004, 1963.

[12] 32 RF 10213, "10CFR Part 50, Licensing of Production and Utilization Facilities, General Design Criteria for Nuclear Power Plant Construction Permits," 1967.

[13]U.S. Atomic Energy Commission, "Seismic Design Classification," Regulatory Guide $1.29,1973$. 
[14]U.S. Atomic Energy Commission, "AEC Licensing Guide, Purpose, Organization, and Contents of Hazards Summary Reports for Power Reactors," 1962.

[15]U.S. Nuclear Regulatory Commission, "Reactor Safety Study, an Assessment of Accident Risks in U.S. Commercial Nuclear Power Plants, Executive Summary," WASH-1400 (NUREG 75/014), 1975.

[16]U.S. Nuclear Regulatory Commission, "Final Disposition of the Systematic Evaluation Program Lessons-Learned Issues," Generic Letter 95-04, 1995.

[17]P. Smith and e. al, "Seismic Safety Margins Research Program," NUREG/CR-2015, 1981.

[18] Commonwealth Edison Company, "Zion Probabilistic Safety Study," 1981.

[19]U.S. Nuclear Regulatory Commission, "PRA Procedures Guide," NUREG/CR-2300, 1983.

[20]U.S. Nuclear Regulatory Commission, "Safety Goals for the Operation of Nuclear Power Plants," Federal Register, 51 FR 30028, 1986.

[21]U.S. Nuclear Regulatory Commission, "Severe Accident Risks: An Assessment for Five U.S. Nuclear Power Plants," NUREG-1150, 1990.

[22]R. Budnitz and e. al, "Recommendations for Probabilistic Seismic Hazard Analysis: Guidance on Uncertainty and Use of Experts," NUREG/CR-6372, 1997.

[23]U.S. Nuclear Regulatory Commission, "Individual Plant Examination Submittal Guidance," NUREG-1335, 1989.

[24]U.S. Nuclear Regulatory Commission, "Procedural and Submittal Guidance for the Individual Plant Examination of External Events (IPEEE) for Severe Accident Vulnerabilities," NUREG-1407, 1991.

[25]U.S. Nuclear Regulatory Commission, "Perspectives Gained from the Individual Plant Examinations of External Events, Final Report," NUREG-1742, 2002.

[26]C. Miller and e. al, "Recommendations for Enhancing Reactor Safety in the 21st Century," USNRC Near-Term Task Force Review of Insights from the Fukushima Dai-Ichi Accident, 2011.

[27]U.S. Nuclear Regulatory Commission, "Guidance for Developing Principal Design Criteria for Non-Light-Water Reactors," Regulatory Guide 1.232, 2018.

[28] U.S. Nuclear Regulatory Commission, "A Proposed Risk Management Regulatory Framework, A Report to NRC Chairman from the Risk Management Task Force," NUREG-2150, 2012.

[29]U.S. Nuclear Regulatory Commission, "Seismic Design Standards and Calculational Methods in the United States and Japan," NUREG/CR-7230, 2017. 
[30]U.S. Nuclear Regulatory Commission, "Toward a More Risk-Informed and PerformanceBased Framework for the Regulation of the Seismic Safety of Nuclear Power Plants," NUREG/CR-7214, 2016.

[31]U.S. Nuclear Regulatory Commission, "Evaluation of the Seismic Design Criteria in ASCE/SEI Standard 43-05 for Application to Nuclear Power Plants," NUREG/CR-6926, 2007.

[32] U.S. Nuclear Regulatory Commission, "Identification and Characterization of Seismic Sources and Determination of Safe Shutdown Earthquake Ground Motion," Regulatory Guide 1.165, 1997.

[33]U.S. Nuclear Regulatory Commission, "A Performance-Based Approach to Define the Site-Specific Earthquake Ground Motion," Regulatory Guide 1.208, 2007.

[34] American Society of Civil Engineers/Structural Engineering Institute, "Seismic Design Criteria for Structures, Systems and Components in Nuclear Facilities," ASCE/SEI 43-05, 2005.

[35]U.S. Nuclear Regulatory Commission, "Policy, Technical, and Licensing Issues Pertaining to Evolutionary and Advanced Light-Water Reactor (ALWR) Designs," Commission Paper SECY-93-087, 1993.

[36]U.S. Nuclear Regulatory Commission, "Staff Requirements Memorandum to SECY-93$087, " 1993$.

[37]U.S. Nuclear Regulatory Commission, "Interim Staff Guidance on Implementation of a Probabilistic Risk Assessment-Based Seismic Margin Analysis for New Reactors," Interim Staff Guidance DC/COL-ISG-020, 2010.

[38]U.S. Nuclear Regulatory Commission, "Guidance on Performing a Seismic Margin Assessment in Response to the March 2012 Request for Information Letter," JLD-ISG2012-04, 2012.

[39] Nuclear Energy Institute, "Risk-Informed Performance-Based Guidance for Non-Light Water Reactor Licensing Basis Development," NEI 18-04 Rev 1, 2019.

[40] Southern Company, "Technology Inclusive Guidance for Non-Light Water Reactor Safety Analysis Report: Content for a Licensing Modernization Project-Based Affirmative Safety Case," 2021.

[41]U.S. Nuclear Regulatory Commission, "Guidelines for Categorizing Structures, Systems, and Components in Nuclear Power Plants According to their Safety Significance," Regulatory Guide 1.201, 2006.

[42] U.S. Nuclear Regulatory Commission, "Standard Review Plan - 17.4 Reliability Assurance Program," 2014.

[43] Southern Company, "Follow-on RIPB Implemenation Guidance Needed for Advanced Non-Light Water Reactors," 2021. 
[44]J. Welsch, "Letter from PG\&E to the U.S. Nuclear Regulatory Commission: Seismic Probabilistic Risk Assessment for the Diablo Canyon Power Plant, Units 1 and 2 Response to NRC Request for Information Pursuant to 10 CFR 50.54(f) Regarding Recommendation 2.1: Seismic of the Near-Term Task Force Review of Insights from the Fukushima Dai-lchi Accident," DCL-18-027, 2018.

[45]U.S. Nuclear Regulatory Commission, "Proposed Rule: Emergency Preparedness for Small Modular Reactors and Other New Technologies," SECY-18-0103, 2018.

[46]U.S. Nuclear Regulatory Commission, "Potential List of Topics for Technology Inclusive Content of Application Project (TICAP) Workshops," 2021.

[47]U.S. Department of Energy, "The DOE Ionizing Radiation Dose Ranges Chart," AU-22 001-2018, 2017.

[48] J. S. Kim and M. C. Kim, "Development of a Software Tool for Seismic Probabilistic Safety Assessment Quantification with a Sufficiently Large Number of Bins for Enhanced Accuracy," Energies, vol. 14, 2021. 


\section{Appendix A: Methodology for Seismic ESF Grouping}

The are several avenues available to calculate the seismic risk associated with the S-LOOP event tree and subsequently derive ESFs and LBEs. The frequency of each event sequence depends on the convolution of the seismic hazard curve with the fragilities of the applicable SSCs. The convolution equation of the hazard curve with a single SSC is provided in Eq. 1 [48],

$$
P=-\int_{0}^{\infty} \frac{d H(a)}{d a} F(a) d a
$$

where $a$ is the ground motion level, $H(a)$ is the exceedance frequency at ground motion level $a$, and $F(a)$ is the seismic failure probability at ground motion level $a$. As this integral can be difficult to calculate directly depending on the type of curve used, it is common in seismic PRAs to discretize the seismic hazard curve into bins of varying ground motion level. The annual frequency of each bin is determined by subtracting the exceedance frequency of the upper range of the bin from the lower range of the bin. This approach results in Eq. 2 [48],

$$
P \approx-\sum_{i=1}^{n}\left[H\left(a_{i+1}\right)-H\left(a_{i}\right)\right] F\left(a_{r, i}\right)
$$

where $n$ is the number of ground motion level bins and $a_{r, i}$ is the representative ground motion level (typically the midpoint) for the $i$-th bin.

When using a binning approach, it is typical to treat each seismic bin as a separate initiator in the PRA and the branching probabilities in the event tree are based on the fragility values of the representative ground motion level for that bin. The result is that a frequency is determined for each event sequence in the event tree for each seismic initiator bin. For the S-LOOP example, if the hazard curve were discretized into 10 bins, this would result in a total of 40 event sequences (10 initiating events $\times 4$ event sequences) when not counting the transfer branch associated with failure to SCRAM scenarios.

When using a binning approach, the resulting event sequences for each seismic initiator bin should not be compared directly to the F-C curve, as there is a dependency that is introduced by the hazard curve binning process. In other words, the greater the number of bins into which the hazard curve is divided, the smaller the frequency interval captured by each seismic initiator bin. Therefore, the frequency of the resulting event sequences will also be reduced with increasing hazard curve discretization.

To develop ESFs from a seismic PRA based on a hazard curve binning approach, the event sequences within the selected event tree must be summed across all seismic initiator bins. Then the cumulative frequency of each event sequence is utilized as the frequency of the associated ESF. In essence, this approach is performing a numerical integration of Eq. 1 and should converge to the analytical solution as the number of bins grows. 
For the S-LOOP analysis, the ESF results were obtained using the summation approach described above. The seismic hazard curve between 0 and $4.0 \mathrm{~g}^{12}$ was divided into 1,000 bins of equal size, with the midpoint of each bin selected as the representative ground motion level. 10,000 Monte Carlo random samples were selected for the associated uncertainty analyses.

${ }^{12}$ Ground motion levels above $4 \mathrm{~g}$ have negligible impact on the results given their low frequency of occurrence for the selected hazard curve. 
Argonne

\section{Nuclear Science and Engineering}

Argonne National Laboratory

9700 South Cass Avenue, Bldg. 208

Argonne, IL 60439

www.anl.gov

Argonne National Laboratory is a U.S. Department of Energy laboratory managed by UChicago Argonne, LLC 